Supporting information for

\title{
Synthesis, Cytotoxicity Evaluation and Computational Insights of Novel 1,4-Diazepane-Based Sigma Ligands
}

Daniele Zampieri ${ }^{\dagger *}$, Sara Fortuna ${ }^{\dagger}$, Antonella Calabretti ${ }^{\dagger}$, Maurizio Romano ${ }^{\ddagger}$, Renzo Menegazzi $^{\ddagger}$, Dirk Schepmann ${ }^{*}$, Bernhard Wünsch ${ }^{\star}$, and Maria Grazia Mamolo ${ }^{\dagger}$.

${ }^{\dagger}$ Department of Chemical and Pharmaceutical Sciences, P.le Europa 1-Via Giorgieri 1, University of Trieste, 34127 Trieste, Italy.

${ }^{\ddagger}$ Department of Life Sciences, Via Valerio 28/1, University of Trieste, 34127 Trieste, Italy.

${ }^{\dagger}$ Institute of Pharmaceutical and Medicinal Chemistry, Corrensstraße 48, 48149 Münster, Germany.

*Corresponding author: dzampieri@units.it

\section{Table of contents}

1. Chemistry

1.1 General remarks

1.2 Synthetic procedure

1.2.1 General procedure for the synthesis of compounds $\mathbf{4 a - g}$

1.2.2 General procedure for the synthesis of compounds $5 \mathbf{5 a - g}$

1.2.3 General procedure of final compounds $\mathbf{2 a - g}$

1.2.4 General procedure of final compounds $\mathbf{3 a - g}$

1.2.5 ${ }^{1} \mathrm{H}-\mathrm{NMR}$ and ${ }^{13} \mathrm{C}-\mathrm{NMR}$ Spectral data for compounds $\mathbf{2 a - g}$ and $\mathbf{3 a - g}$

2. Computational details

2.1 Protein preparation

2.2 Molecule preparation and docking

2.3 Molecular dynamics simulations

3. Binding studies

3.1 Materials

3.2 Preparation of membrane homogenates from pig brain cortex

3.3 Preparation of membrane homogenates from rat liver

3.4 Preparation of membrane homogenates for GluN2b

3.5 Protein determination

3.6 General procedures for the binding assays

3.7 Performance of binding assays

3.7.1 Ifenprodil binding site of GluN2B subunit containing NMDA receptors

$3.7 .3 \sigma 1$ receptor assay

$3.7 .4 \sigma 2$ receptor assay

4. Cytotoxicity assay

5. Antioxidant activity

5.1 ABTS radical scavenging activity

5.2 Hydrogen peroxide radical scavenging activity

6. Drug likeness prediction 


\section{Chemistry}

\subsection{General remarks}

Commercially available chemicals were of reagents grade and used as received. Dry column vacuum chromatography (DCVC) was performed using Silica Gel 40 (230-400 mesh, Sigma-Aldrich-Merck) and Celite 545 was used for filtration. Reaction courses and product mixtures were routinely monitored by thin-layer chromatography (TLC) on silica gel precoated $\mathrm{F}_{254}$ Merck plates. Infrared spectra were recorded on a Jasco 4700 spectrophotometer in nujol mulls. Nuclear magnetic resonance spectra were determined on a Varian $400 \mathrm{MHz}$ or $500 \mathrm{MHz}$ (400 and $500 \mathrm{MHz}$ for ${ }^{1} \mathrm{H}-\mathrm{NMR}$ whereas 101 and 126 $\mathrm{MHz}$ for $\left.{ }^{13} \mathrm{C}-\mathrm{NMR}\right)$. Chemical shifts are reported as $\delta(\mathrm{ppm})$ in $\mathrm{CDCl}_{3}$ solution $(0.05 \% \mathrm{TMS})$ related to tetramethylsilane employed as the internal standard $\left(\mathrm{CDCl}_{3}, \delta=7.26 \mathrm{ppm}\right.$ for ${ }^{1} \mathrm{H}-\mathrm{NMR}$ and $\delta=77.2$ for $\left.{ }^{13} \mathrm{C}-\mathrm{NMR}\right) ; 10 \mu \mathrm{L}$ of $\mathrm{D}_{2} \mathrm{O}$ was added to assign $\mathrm{NH}$ protons. Coupling constants $(J)$ are reported in $\mathrm{Hz}$ and the splitting abbreviations used are: $\mathrm{s}$, singlet; $\mathrm{d}$, doublet; dd, doublet of doublets; $\mathrm{t}$, triplet; dt, doublet of triplets; td, triplet of doublets; q, quartet; m, multiplet; br, broad. Microanalyses $(\mathrm{C}, \mathrm{H}, \mathrm{N})$ were carried out with Elementar Vario ELIII apparatus and were in agreement with theoretical values $\pm 0.4 \%$. ESIMS spectra (LRMS) were obtained on a Bruker Daltonics Esquire 4000 spectrometer by infusion of a solution of the sample in MeOH (HPLC grade).

\subsection{Synthetic procedure}

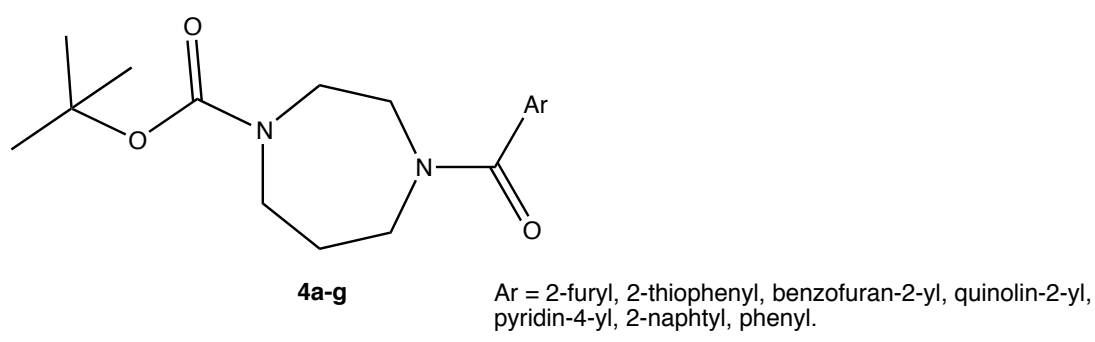

\subsubsection{General procedure for the synthesis of compounds 4a-g}

$500 \mathrm{mg}(2.50 \mathrm{mmol})$ of tert-butyl 1,4-diazepane-1-carboxylate and an equimolar amount of $\mathrm{Et}_{3} \mathrm{~N}$ were dissolved in $25 \mathrm{~mL}$ of $\mathrm{CH}_{2} \mathrm{Cl}_{2}$ solution and the mixture was maintained, under stirring, at $0^{\circ} \mathrm{C}$ on an icebath. An equimolar amount of the appropriate aroyl chloride $(2.50 \mathrm{mmol})$ was added and the reaction was monitored by TLC $\left(\mathrm{CH}_{2} \mathrm{Cl}_{2} / \mathrm{EtOH} 95: 5\right)$ until it was completed. $2 \mathrm{~N} \mathrm{KOH}$ solution was added (until $\mathrm{pH}=8)$, and the organic phase was washed with distilled water $(3 \times 50 \mathrm{~mL})$. The collected organic phase was dried over $\mathrm{Na}_{2} \mathrm{SO}_{4}$, filtered and evaporated under vacuum to afford an oily residue which was used without further purification.

\section{tert-butyl 4-(furan-2-carbonyl)-1,4-diazepane-1-carboxylate (4a)}

Yellow oil; Yield: 91\%; ${ }^{1} \mathrm{HNMR}\left(\mathrm{CDCl}_{3}, \delta\right.$, ppm): 1.45 (s, 9H, $\left.\mathrm{C}\left(\mathrm{CH}_{3}\right)_{3}\right), 1.95$ (m, 2H, diazep.), 3.383.88 (m br, $8 \mathrm{H}$, diazep.), 6.47 (m, 1H, fur.), 7.04 (m, 1H, fur.), 7.47 (m, 1H, fur.). LRMS (ESI ${ }^{+}$) for $\mathrm{C}_{15} \mathrm{H}_{22} \mathrm{~N}_{2} \mathrm{O}_{4}$ : required $m / z 295.2$, found $m / z 295.2[\mathrm{M}+\mathrm{H}]^{+}$. 
tert-butyl 4-(thiophene-2-carbonyl)-1,4-diazepane-1-carboxylate (4b)

Yellow oil; Yield: 98\%; ${ }^{1} \mathrm{HNMR}\left(\mathrm{CDCl}_{3}, \delta, \mathrm{ppm}\right): 1.42\left(\mathrm{~s}, 9 \mathrm{H}, \mathrm{C}\left(\mathrm{CH}_{3}\right)_{3}\right), 1.93(\mathrm{~m} \mathrm{br}, 2 \mathrm{H}$, diazep.), 3.42 $(\mathrm{t}, 1 \mathrm{H}$, diazep. $\mathrm{J}=5.6 \mathrm{~Hz}), 3.50(\mathrm{~m}, 1 \mathrm{H}$, diazep.), $3.66(\mathrm{~m}, 1 \mathrm{H}$, diazep.), $3.70(\mathrm{t}, 2 \mathrm{H}$, diazep. $\mathrm{J}=6.0), 3.79$ (m, 2H, diazep.), 7.03 (t, 1H, thioph. $\mathrm{J}=4.4 \mathrm{~Hz}$ ), 7.33 (br 1H, thioph.), 7.43 (br, 1H, thioph.). LRMS $\left(\mathrm{ESI}^{+}\right.$) for $\mathrm{C}_{15} \mathrm{H}_{22} \mathrm{~N}_{2} \mathrm{O}_{3} \mathrm{~S}$ : required $\mathrm{m} / z$ 311.1, found $\mathrm{m} / \mathrm{z} 311.2[\mathrm{M}+\mathrm{H}]^{+}$.

\section{tert-butyl 4-(benzofuran-2-carbonyl)-1,4-diazepane-1-carboxylate (4c)}

Pale yellow oil; Yield: 99\%; ${ }^{1} \mathrm{HNMR}\left(\mathrm{CDCl}_{3}, \delta\right.$, ppm): $1.46\left(\mathrm{~s}, 9 \mathrm{H}, \mathrm{C}\left(\mathrm{CH}_{3}\right)_{3}\right), 2.01$ (m br, 2H, diazep.), 3.43-3.93 (m br, 8H, diazep.), 7.28 (t, 1H, arom. J = $7.6 \mathrm{~Hz}$ ), 7.34 (s, 1H, $\mathrm{H}_{3}$-arom.), 7.39 (t, 1H, arom. J $=7.6 \mathrm{~Hz}), 7.50(\mathrm{~d}, 1 \mathrm{H}$, arom. $\mathrm{J}=8.4 \mathrm{~Hz}), 7.65(\mathrm{~d}, 1 \mathrm{H}$, arom. $\mathrm{J}=7.6 \mathrm{~Hz})$. LRMS $\left(\mathrm{ESI}^{+}\right)$for $\mathrm{C}_{19} \mathrm{H}_{24} \mathrm{~N}_{2} \mathrm{O}_{4}$ : required $m / z 345.2$, found $m / z 345.0[\mathrm{M}+\mathrm{H}]^{+}$.

tert-Butyl 4-(quinoline-2-carbonyl)-1,4-diazepane-1-carboxylate (4d)

Light-violet oil; Yield: 96\%; ${ }^{1} \mathrm{HNMR}\left(\mathrm{CDCl}_{3}, \delta\right.$, ppm): $1.49\left(\mathrm{~m}, 9 \mathrm{H}, \mathrm{C}\left(\mathrm{CH}_{3}\right)_{3}\right), 1.92(\mathrm{~m}, 1 \mathrm{H}$, diazep.), 2.01 (m, 1H, diazep.), 3.55 (m, 2H, diazep.), 3.65 (m, 4H, diazep.), 3.77 (t, 1H, diazep. J = 6.0 Hz), 3.88 (m, 1H, diazep.), 7.60 (m, 1H, arom.), 7.75 (m, 2H, arom.), 7.85 (d, 1H, arom. J = 8.0 Hz), 8.06 (d, $1 \mathrm{H}$, arom. $\mathbf{J}=8.4 \mathrm{~Hz}), 8.25(\mathrm{~d}, 1 \mathrm{H}$, arom. $\mathbf{J}=8.4 \mathrm{~Hz})$. LRMS $\left(E S I^{+}\right)$for $\mathrm{C}_{20} \mathrm{H}_{25} \mathrm{~N}_{3} \mathrm{O}_{3}$ : required $m / z$ 356.2, found $m / z 356.2[\mathrm{M}+\mathrm{H}]^{+}$.

\section{tert-Butyl 4-isonicotinoyl-1,4-diazepane-1-carboxylate (4e)}

Pale yellow oil; Yield: 98\%; ${ }^{1} \mathrm{HNMR}\left(\mathrm{CDCl}_{3}, \delta\right.$, ppm): $1.45\left(\mathrm{~m}, 9 \mathrm{H}, \mathrm{C}\left(\mathrm{CH}_{3}\right)_{3}\right), 1.93$ (m, 1H, diazep.), 2.87 (m, 1H, diazep.), 3.41 (m, 3H, diazep.), 3.60 (t, 1H, diazep. J = 6.0 Hz), 3.68 (t, 1H, diazep. $\mathrm{J}=5.6$ $\mathrm{Hz}), 3.78$ (t, 1H, diazep. $\mathrm{J}=5.6 \mathrm{~Hz}), 7.60(\mathrm{~m}, 1 \mathrm{H}$, arom.), $7.24(\mathrm{dd}, 2 \mathrm{H}$, arom. pyr. $\mathrm{J}=2.0,8.8 \mathrm{~Hz}), 8.66$ $\left(\mathrm{d}, 2 \mathrm{H}\right.$, arom. pyr. $\mathrm{J}=1.6,8.0 \mathrm{~Hz}$ ). LRMS $\left(\mathrm{ESI}^{+}\right)$for $\mathrm{C}_{15} \mathrm{H}_{22} \mathrm{~N}_{2} \mathrm{O}_{4}$ : required $\mathrm{m} / \mathrm{z} 306.2$, found $\mathrm{m} / z .306 .3$ $[\mathrm{M}+\mathrm{H}]^{+}$.

tert-Butyl 4-(1-naphthoyl)-1,4-diazepane-1-carboxylate (4f)

Yellow oil; Yield: 96\%; ${ }^{1} \mathrm{HNMR}\left(\mathrm{CDCl}_{3}, \delta\right.$, ppm): $1.48\left(\mathrm{~m}, 9 \mathrm{H}, \mathrm{C}\left(\mathrm{CH}_{3}\right)_{3}\right), 2.11$ (m, 2H, diazep.), 3.26 (m, 3H, diazep), 3.52 (m, 3H, diazep.), 3.71 (m, 1H, diazep.), 4.12 (m, 1H, diazep.), 7.40 (dd, 1H, arom. $\mathrm{J}=1.6,7.2 \mathrm{~Hz}$ ), 7.49 (m, 3H, arom.), 7.79 (m, 1H, arom.), 7.87 (m, 2H, arom.). LRMS (ESI ${ }^{+}$) for $\mathrm{C}_{21} \mathrm{H}_{26} \mathrm{~N}_{2} \mathrm{O}_{3}$ : required $m / z$ 355.2, found $m / z 355.2[\mathrm{M}+\mathrm{H}]^{+}$.

\section{tert-Butyl 4-benzoyl-1,4-diazepane-1-carboxylate (4g)}

Yellow oil; Yield: 92\%; ${ }^{1} \mathrm{HNMR}\left(\mathrm{CDCl}_{3}, \delta\right.$, ppm): 1.46 (s, 9H, $\left.\mathrm{C}\left(\mathrm{CH}_{3}\right)_{3}\right), 1.98(\mathrm{~m}, 2 \mathrm{H}$, diazep.), $3.43(\mathrm{~m}$, $5 \mathrm{H}$, diazep), 3.61-3.79 (m, 3H, diazep.), 7.38 (m, 5H, arom.). LRMS (ESI ${ }^{+}$) for $\mathrm{C}_{17} \mathrm{H}_{24} \mathrm{~N}_{2} \mathrm{O}_{3}:$ required $\mathrm{m} / \mathrm{z}$ 305.2, found $\mathrm{m} / \mathrm{z} 305.1[\mathrm{M}+\mathrm{H}]^{+}$. 


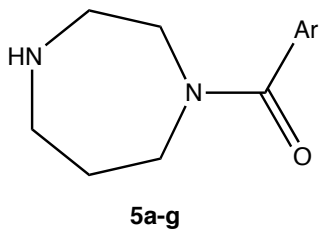

$\operatorname{Ar}=2$-furyl, 2-thiophenyl, benzofuran-2-yl, quinolin-2-yl, pyridin-4-yl, 2-naphtyl, phenyl.

\subsubsection{General procedure for the synthesis of compounds 5a-g}

$300 \mathrm{mg}(1.0 \mathrm{mmol})$ of tert-butyl 4-(furan-2-carbonyl)-1,4-diazepane-1-carboxylate $4 \mathbf{a}$ and $2 \mathrm{~mL}$ of trifluoroacetic acid were dissolved in few $\mathrm{mL}$ of $\mathrm{CH}_{2} \mathrm{Cl}_{2}$ solution at $\mathrm{rt}$ and stirred until the reaction was completed (TLC: $\mathrm{CH}_{2} \mathrm{Cl}_{2} / \mathrm{EtOH} 90: 10$ ). $2 \mathrm{~N} \mathrm{KOH}$ solution was added (until $\mathrm{pH}=8$ ) and the organic layer was washed with distilled water $(3 \times 50 \mathrm{~mL})$. The collected organic phase was dried over $\mathrm{Na}_{2} \mathrm{SO}_{4}$, filtered and concentrated in vacuo to afford an oily residue which was used without further purification.

\section{(1,4-Diazepan-1-yl)(furan-2-yl)methanone (5a)}

Yellow oil; Yield: 76\%; ${ }^{1} \mathrm{HNMR}\left(\mathrm{CDCl}_{3}, \delta, \mathrm{ppm}\right): 1.78(\mathrm{~s}, 1 \mathrm{H}, \mathrm{NH}), 1.90(\mathrm{~m} \mathrm{br}, 2 \mathrm{H}$, diazep.), $2.91(\mathrm{t}$, $2 \mathrm{H}$, diazep. $\mathrm{J}=6.0 \mathrm{~Hz}$ ), 3.04 (m br, $2 \mathrm{H}$, diazep.), 3.79 (m br, 4H, diazep.), 6.46 (dd, $1 \mathrm{H}, \mathrm{H}_{4}$-fur. $\mathrm{J}=1.6$, $3.2 \mathrm{~Hz}$ ), $7.04\left(\mathrm{~d}, 1 \mathrm{H}, \mathrm{H}_{3}\right.$-fur. $\mathrm{J}=4.0 \mathrm{HZ}$ ), 7.46 (br, $1 \mathrm{H}, \mathrm{H}_{5}$-fur.). LRMS (ESI ${ }^{+}$) for $\mathrm{C}_{10} \mathrm{H}_{14} \mathrm{~N}_{2} \mathrm{O}_{2}$ : required $m / z$ 195.1, found $m / z 195.0[\mathrm{M}+\mathrm{H}]^{+}$.

\section{(1,4-Diazepan-1-yl)(thiophen-2-yl)methanone (5b)}

Yellow oil; Yield: $65 \%$; ${ }^{1} \mathrm{HNMR}\left(\mathrm{CDCl}_{3}, \delta\right.$, ppm): $1.90(\mathrm{~m} \mathrm{br}, 3 \mathrm{H}, 2 \mathrm{H}$ diazep. and $\mathrm{NH}), 2.94(\mathrm{t}, 2 \mathrm{H}$, diazep. $\mathrm{J}=6.0 \mathrm{~Hz}$ ), 3.04 ( $\mathrm{m} \mathrm{br}, 2 \mathrm{H}$, diazep.), 3.77 (m, 4H, diazep.), 7.03 (dd, 1H, $\mathrm{H}_{4}$-thioph. $\mathrm{J}=3.6,5.2$ $\mathrm{Hz}$ ), 7.33 (d br, 1H, $\mathrm{H}_{3}$-thioph. $\mathrm{J}=2.8 \mathrm{~Hz}$ ), $7.43\left(\mathrm{dd}, 1 \mathrm{H}, \mathrm{H}_{5}\right.$-thioph. $\mathrm{J}=1.2,5.2 \mathrm{~Hz}$ ). LRMS (ESI ${ }^{+}$) for $\mathrm{C}_{10} \mathrm{H}_{14} \mathrm{~N}_{2} \mathrm{OS}$ : required $\mathrm{m} / \mathrm{z}, 211.1$, found $\mathrm{m} / \mathrm{z} 211.1[\mathrm{M}+\mathrm{H}]^{+}$.

\section{Benzofuran-2-yl(1,4-diazepan-1-yl)methanone (5c)}

Pale yellow oil; Yield: 90\%; ${ }^{1} \mathrm{HNMR}\left(\mathrm{CDCl}_{3}, \delta\right.$, ppm): 2.03 (m br, 2H, diazep.), 2.79 (m br, 1H, $\mathrm{NH}$ ), 3.01 (t, 2H, diazep. J = 5.6 Hz), 3.15 (m br, 2H, diazep.), 3.87 (m, 4H, diazep.), 7.28 (m, 1H, arom.), $7.33(\mathrm{~d}, 1 \mathrm{H}$, arom. $\mathrm{J}=0.8 \mathrm{~Hz}), 7.39(\mathrm{td}, 1 \mathrm{H}$, arom. $\mathrm{J}=1.2,7.2 \mathrm{~Hz}), 7.50(\mathrm{~d}, 1 \mathrm{H}$, arom. $\mathrm{J}=8.4 \mathrm{~Hz}), 7.64$ $(\mathrm{d}, 1 \mathrm{H}$, arom. $\mathrm{J}=8 \mathrm{~Hz})$. LRMS $\left(\mathrm{ESI}^{+}\right)$for $\mathrm{C}_{14} \mathrm{H}_{16} \mathrm{~N}_{2} \mathrm{O}_{2}$ : required $m / z 245.1$, found $\mathrm{m} / \mathrm{z} 245.0[\mathrm{M}+\mathrm{H}]^{+}$.

\section{(1,4-Diazepan-1-yl)(quinolin-2-yl)methanone (5d)}

Pale yellow oil; Yield: 91\%; ${ }^{1} \mathrm{HNMR}\left(\mathrm{CDCl}_{3}, \delta\right.$, ppm): $1.88(\mathrm{q}, 1 \mathrm{H}$, diazep. $\mathrm{J}=6.0 \mathrm{~Hz}), 2.01(\mathrm{q}, 1 \mathrm{H}$, diazep. $\mathrm{J}=6.0 \mathrm{~Hz}), 2.16(\mathrm{~m} \mathrm{br}, 1 \mathrm{H} \mathrm{NH}), 3.05(\mathrm{~m}, 3 \mathrm{H}$, diazep.), $3.14(\mathrm{~m}, 1 \mathrm{H}$, diazep.), $3.68(\mathrm{~m}, 2 \mathrm{H}$, diazep.), 3.88 (m, 2H, diazep.), 7.59 (m, 1H, arom.), 7.72 (m, 2H, arom.), 7.84 (dt, $1 \mathrm{H}$, arom. $\mathrm{J}=1.6,8.0$ $\mathrm{Hz}), 8.08(\mathrm{dd}, 1 \mathrm{H}$, arom. J = 4.0, $7.6 \mathrm{~Hz}), 8.25(\mathrm{~d}, 1 \mathrm{H}$, arom. $\mathrm{J}=7.6 \mathrm{~Hz})$. LRMS $\left(\mathrm{ESI}^{+}\right)$for $\mathrm{C}_{15} \mathrm{H}_{17} \mathrm{~N}_{3} \mathrm{O}$ : required $\mathrm{m} / \mathrm{z} 256.1$, found $\mathrm{m} / \mathrm{z} 256.1[\mathrm{M}+\mathrm{H}]^{+}$.

\section{(1,4-Diazepan-1-yl)(pyridin-4-yl)methanone (5e)}

Pale yellow oil; Yield: 74\%; ${ }^{1} \mathrm{HNMR}\left(\mathrm{CDCl}_{3}, \delta\right.$, ppm): $1.63(\mathrm{q}, 1 \mathrm{H}$, diazep. J = 6.0 Hz), $1.86(\mathrm{~m}, 2 \mathrm{H}, 1 \mathrm{H}$ diazep. and $\mathrm{NH}$ ), 2.85 (m, 3H NH), 3.00 (m, 1H, diazep.), 3.32 (m, 2H, diazep.), 3.71 (m, 2H, diazep.), 
7.59 (m, $1 \mathrm{H}$, arom.), 7.22 (m, $2 \mathrm{H}$, arom.), 8.61 (m, 1H, arom.). LRMS (ESI ${ }^{+}$) for $\mathrm{C}_{11} \mathrm{H}_{15} \mathrm{~N}_{3} \mathrm{O}$ : required $m / z$ 206.1, found $m / z$ 206.1 [M+H] .

\section{(1,4-Diazepan-1-yl)(naphthalen-1-yl)methanone (5f)}

Yellow oil; Yield: 86\%; ${ }^{1} \mathrm{HNMR}\left(\mathrm{CDCl}_{3}, \delta\right.$, ppm): 1.55 (q, 1H, diazep. J = 6.0 Hz), 1.78 (s br, $\left.1 \mathrm{H} \mathrm{NH}\right)$, $2.02(\mathrm{~m}, 1 \mathrm{H}$, diazep.), $2.71(\mathrm{t}, 1 \mathrm{H}$ diazep. $\mathrm{J}=5.6 \mathrm{~Hz}), 2.89(\mathrm{t}, 1 \mathrm{H}$, diazep. $\mathrm{J}=5.6 \mathrm{~Hz}), 3.00(\mathrm{~m}, 1 \mathrm{H}$, diazep.), $3.15(\mathrm{td}, 1 \mathrm{H}$, diazep. $\mathrm{J}=0.8,4.8 \mathrm{~Hz}), 3.27(\mathrm{~m}, 2 \mathrm{H}$, diazep.), $3.83(\mathrm{~m}, 1 \mathrm{H}$, diazep.), $4.04(\mathrm{~m}, 1 \mathrm{H}$, diazep.), 7.41 (m, 1H, arom.), 7.45-7.54 (m, 3H, arom.), 7.85 (m, 3H, arom.). LRMS (ESI ${ }^{+}$) for $\mathrm{C}_{16} \mathrm{H}_{18} \mathrm{~N}_{2} \mathrm{O}$ : required $m / z, 255.1$, found $m / z, 255.0[\mathrm{M}+\mathrm{H}]^{+}$.

\section{(1,4-Diazepan-1-yl)(phenyl)methanone (5g)}

Pale yellow oil; Yield: 89\%; ${ }^{1} \mathrm{HNMR}\left(\mathrm{CDCl}_{3}, \delta\right.$, ppm): $1.68(\mathrm{q}, 1 \mathrm{H}$, diazep. $\mathrm{J}=6.0 \mathrm{~Hz}), 1.72(\mathrm{~s}$ br, $1 \mathrm{H}$ $\mathrm{NH}), 1.92(\mathrm{q}, 1 \mathrm{H}$, diazep. $\mathrm{J}=6.0 \mathrm{~Hz}), 2.82(\mathrm{t}, 1 \mathrm{H}$ diazep. $\mathrm{J}=5.6 \mathrm{~Hz}), 2.90(\mathrm{t}, 1 \mathrm{H}$ diazep. $\mathrm{J}=5.6 \mathrm{~Hz})$, $2.94(\mathrm{t}, 1 \mathrm{H}$ diazep. $\mathrm{J}=6.0 \mathrm{~Hz}), 3.06(\mathrm{t}, 1 \mathrm{H}$ diazep. $\mathrm{J}=5.6 \mathrm{~Hz}), 3.44(\mathrm{~m}, 2 \mathrm{H}$, diazep.), $3.77(\mathrm{~m}, 2 \mathrm{H}$, diazep.), 7.37 (br, 5H, arom.). LRMS (ESI ${ }^{+}$) for $\mathrm{C}_{12} \mathrm{H}_{16} \mathrm{~N}_{2} \mathrm{O}$ : required $m / z$ 205.1, found $m / z, 205.1[\mathrm{M}+\mathrm{H}]^{+}$.

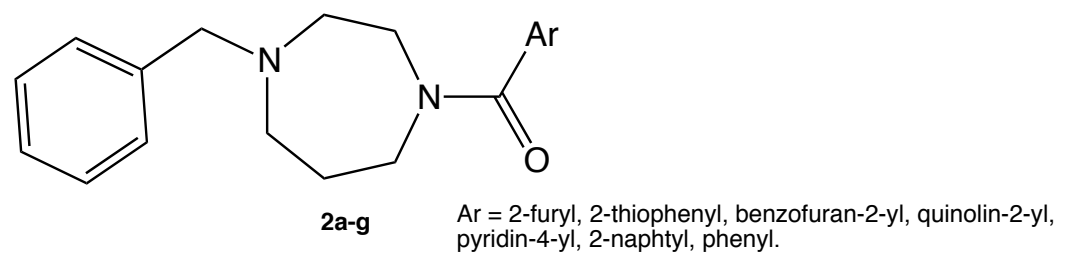

\subsubsection{General synthesis of final compounds $2 \mathrm{a}-\mathrm{g}$}

A solution of 1-benzyl-1,4-diazepane (200 mg, $1.05 \mathrm{mmol})$ and $\mathrm{Et}_{3} \mathrm{~N}$ (110 mg, $\left.1.26 \mathrm{mmol}\right)$ in $25 \mathrm{~mL}$ of $\mathrm{CH}_{2} \mathrm{Cl}_{2}$ was stirred on an ice-bath at $0^{\circ} \mathrm{C}$. The appropriate aroyl chloride $(1.05 \mathrm{mmol})$ was then added dropwise and the reaction was controlled by TLC $\left(\mathrm{CH}_{2} \mathrm{Cl}_{2} / \mathrm{EtOH} 9: 1\right)$. At the end of the reaction the mixture was washed with aqueous $2 \mathrm{~N} \mathrm{KOH}$ solution $(1 \times 25 \mathrm{~mL})$, water $(1 \times 25 \mathrm{~mL})$ and brine $(1 \times 25$ $\mathrm{mL})$. The collected organic layer was dried $\left(\mathrm{Na}_{2} \mathrm{SO}_{4}\right)$, filtered and concentrated under vacuum to afford a chromatographically pure oily residue.

\section{(4-Benzyl-1,4-diazepan-1-yl)(furan-2-yl)methanone (2a)}

Pale orange oil; yield: $87 \%$; I.R. (nujol, $\left.\mathrm{cm}^{-1}\right): 1621 ;{ }^{1} \mathrm{HNMR}\left(\mathrm{CDCl}_{3}, \delta, \mathrm{ppm}\right): 1.92$ (m, 2H, diazep.), 2.64 (m, 2H, diazep.), 2.75 (m, 2H, diazep.), 3.60 (s, 1H, Ph-CHH), 3.63 (s, 1H, Ph-CHH), 3.64-3.74 (m, 4H, diazep.), 6.70 (dd, $1 \mathrm{H}$, fur. $\mathrm{J}=2.0,7.2 \mathrm{~Hz}), 7.20-7.30(\mathrm{~m}, 6 \mathrm{H}$, arom.), 8.25 (dd, $1 \mathrm{H}$, fur. $\mathrm{J}=2.0,6.4$ $\mathrm{Hz}) .{ }^{13} \mathrm{CNMR}\left(\mathrm{CDCl}_{3}, \delta\right.$, ppm): 26.87, 28.57, 45.86, 46.19, 54.13, 55.05, 56.65, 62.22, 111.16, 116.05, 127.15, 128.29, 128.78, 128.91, 138.29, 138.59, 143.67, 143.80, 143.87, 148.24, 160.19. LRMS (ESI ${ }^{+}$): required $m / z 285.2$, found $m / z 285.0[\mathrm{M}+\mathrm{H}]^{+}$; elemental analysis calcd $(\%)$ for $\mathrm{C}_{17} \mathrm{H}_{20} \mathrm{~N}_{2} \mathrm{O}_{2}: \mathrm{C} 71.81, \mathrm{H}$ 7.09, N 9.85; found: C 71.95, H 7.30, N 9.92.

\section{(4-Benzyl-1,4-diazepan-1-yl)(thiophen-2-yl)methanone (2b)}


Pale yellow oil; yield: $92 \%$; I.R. (nujol, $\left.\mathrm{cm}^{-1}\right)$ : 1609; ${ }^{1} \mathrm{HNMR}\left(\mathrm{CDCl}_{3}, \delta, \mathrm{ppm}\right): 1.91$ (m, 2H, diazep.), 2.73 (m, 4H, diazep.), 3.60 (s, 2H, $\mathrm{Ph}-\mathrm{CH}_{2}$ ), 3.74 (m, 4H, diazep.), 6.99 (t br, 1H, thioph. J = 4.4 Hz), 7.20-7.30 (m, 6H, Ph e thioph.), $7.38(\mathrm{~d}, 1 \mathrm{H}$, thioph. $\mathrm{J}=5.2 \mathrm{~Hz}) .{ }^{13} \mathrm{CNMR}\left(\mathrm{CDCl}_{3}, \delta, \mathrm{ppm}\right): 27.17,29.08$, 46.09, 46.66, 48.84, 49.74, 54.19, 55.03, 55.75, 56.28, 62.33, 126.70, 127.08, 128.30, 128.72, 128.76, 138.20, 138.93, 164.31. LRMS $\left(\mathrm{ESI}^{+}\right)$: required $\mathrm{m} / z$ 301.1, found $\mathrm{m} / z, 301.1[\mathrm{M}+\mathrm{H}]^{+}$; elemental analysis calcd (\%) for $\mathrm{C}_{17} \mathrm{H}_{20} \mathrm{~N}_{2} \mathrm{OS}$ : C 67.97, H 6.71, N 9.32; found: C 68.22, H 6.79, N 9.44.

\section{Benzofuran-2-yl(4-benzyl-1,4-diazepan-1-yl)methanone (2c)}

Pale yellow oil; yield: $91 \%$; I.R. (nujol, $\left.\mathrm{cm}^{-1}\right): 1633 ;{ }^{1} \mathrm{HNMR}\left(\mathrm{CDCl}_{3}, \delta\right.$, ppm): 1.97 (m, 2H, diazep.), 2.67 (m, 2H, diazep.), 2.81 (m, 2H, diazep.) 3.64 (s, 2H, $\left.\mathrm{Ph}_{-} \mathrm{CH}_{2}\right), 3.69(\mathrm{~m}, 2 \mathrm{H}$, diazep.), 3.87 (m, 2H, diazep.), 7.24-7.38 (m, 8H, arom.), 7.50 (t, 1H, arom. $\mathrm{J}=8.8 \mathrm{~Hz}), 7.63$ (dd, 1H, arom. J = 2.8, 8.0 Hz). ${ }^{13} \mathrm{CNMR}\left(\mathrm{CDCl}_{3}, \delta, \mathrm{ppm}\right): 27.01,29.04,46.17,46.87,47.99,48.90,54.30,54.92,55.28,56.68,62.39$, $111.51,111.85,122.20,123.51,126.28,126.31,127.03,127.09,128.31,128.72,128.75,128.80,139.00$, 149.55, 154.61, 160.94. LRMS $\left(\mathrm{ESI}^{+}\right)$: required $\mathrm{m} / \mathrm{z}$ 335.2, found $\mathrm{m} / \mathrm{z} 335.0[\mathrm{M}+\mathrm{H}]^{+}$; elemental analysis calcd (\%) for $\mathrm{C}_{21} \mathrm{H}_{22} \mathrm{~N}_{2} \mathrm{O}_{2}$ : C 75.42, H 6.63, N 8.38; found: C 75.40, H 6.80, N 8.45.

\section{(4-Benzyl-1,4-diazepan-1-yl)(quinolin-2-yl)methanone (2d)}

Reddish oil; yield: $83 \%$; I.R. (nujol, $\left.\mathrm{cm}^{-1}\right): 1630 ;{ }^{1} \mathrm{HNMR}\left(\mathrm{CDCl}_{3}, \delta\right.$, ppm): 1.81 (q, 1H, diazep. $\mathrm{J}=6.0$ $\mathrm{Hz}$ ), 1.97 (q, 1H, diazep. J = 6.0 Hz), 2.65 (m,3H, diazep.), 2.82 (m, 1H, diazep.), $3.58(\mathrm{~s}, 1 \mathrm{H}, \mathrm{Ph}-\mathrm{CH}$ ), 3.61 (m, 2H, diazep.), 3.64 (s, 1H, Ph-CHH), 3.84 (m, 2H, diazep.), 7.14-7.33 (m, 5H, arom.), 7.50 (m, $1 \mathrm{H}$, arom.), 7.65 (m, 2H, arom.), 7.75 (dd, 1H, arom. J = 5.2, $8.8 \mathrm{~Hz}), 8.04$ (t, 1H, arom. J = 8.0 Hz), 8.16 $(\mathrm{dd}, 1 \mathrm{H}$, arom. $\mathrm{J}=6.0,9.2 \mathrm{~Hz}) .{ }^{13} \mathrm{CNMR}\left(\mathrm{CDCl}_{3}, \delta, \mathrm{ppm}\right): 26.92,28.87,45.79,46.62,48.43,49.40$, $54.20,54.70,55.31,56.49,62.28,62.31,120.36,120.48,127.00,127.02,127.38,127.63,127.65,127.84$, $127.88,128.15,128.23,128.27,128.68,128.71,128.78,129.60,129.64129 .96,137.04,139.03,139.10$, 146.58, 146.63, 154.57, 169.00, 169.07. LRMS $\left(\mathrm{ESI}^{+}\right)$: required $\mathrm{m} / \mathrm{z} 346.2$, found $\mathrm{m} / \mathrm{z} 346.2[\mathrm{M}+\mathrm{H}]^{+}$; elemental analysis calcd (\%) for $\mathrm{C}_{22} \mathrm{H}_{23} \mathrm{~N}_{3} \mathrm{O}$ : C 76.49, $\mathrm{H}$ 6.71, N 12.16; found: C 76.39, H 6.55, N 11.84.

\section{(4-Benzyl-1,4-diazepan-1-yl)(pyridin-4-yl)methanone (2e)}

Yellow oil; yield: $74 \%$; I.R. (nujol, $\left.\mathrm{cm}^{-1}\right): 1632 ;{ }^{1} \mathrm{HNMR}\left(\mathrm{CDCl}_{3}, \delta\right.$, ppm): 1.76 (q, 1H, diazep. $\mathrm{J}=6.0$ $\mathrm{Hz}), 1.96(\mathrm{q}, 1 \mathrm{H}$, diazep. $\mathrm{J}=6.0 \mathrm{~Hz}), 2.56(\mathrm{t}, 1 \mathrm{H}$, diazep. $\mathrm{J}=5.2 \mathrm{~Hz}), 2.62(\mathrm{t}, 1 \mathrm{H}$, diazep. $\mathrm{J}=5.6 \mathrm{~Hz})$, $2.72(\mathrm{t}, 1 \mathrm{H}$, diazep. $\mathrm{J}=5.6 \mathrm{~Hz}), 2.79(\mathrm{t}, 1 \mathrm{H}$, diazep. $\mathrm{J}=5.2 \mathrm{~Hz}), 3.38(\mathrm{~m}, 2 \mathrm{H}$, diazep.), 3.61 (s, 1H, Ph$\mathrm{CHH}), 3.66$ (s, 1H, Ph-CHH), 3.77 (m, 2H, diazep.), 7.24-7.33 (m, 7H, arom.), 8.66 (dd, 2H, arom. J =

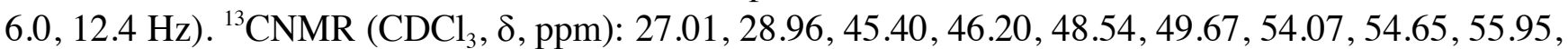
$56.00,62.61,120.89,121.00,126.82,127.15,127.22,128.16,128.34,128.68,128.75,128.77,138.73$, 138.82, 144.49, 150.20, 150.23, 168.97. LRMS (ESI ${ }^{+}$): required $\mathrm{m} / z$ 296.2, found $\mathrm{m} / \mathrm{z} 296.1[\mathrm{M}+\mathrm{H}]^{+}$; elemental analysis calcd (\%) for $\mathrm{C}_{18} \mathrm{H}_{21} \mathrm{~N}_{3} \mathrm{O}$ : C 73.19, H 7.17, N 14.23; found: C 73.40, H 7.33, N 14.45.

\section{(4-Benzyl-1,4-diazepan-1-yl)(naphthalen-1-yl)methanone (2f)}

Yellow oil; yield: $80 \%$; I.R. (nujol, $\left.\mathrm{cm}^{-1}\right)$ : 1630; ${ }^{1} \mathrm{HNMR}\left(\mathrm{CDCl}_{3}, \delta, \mathrm{ppm}\right): 1.66$ (m br, 1H, diazep.), 2.06 $(\mathrm{q}, 1 \mathrm{H}$, diazep. $\mathrm{J}=4.8 \mathrm{~Hz}), 2.47(\mathrm{~m}, 1 \mathrm{H}$, diazep.), $2.62(\mathrm{t}, 1 \mathrm{H}$, diazep. $\mathrm{J}=4.4 \mathrm{~Hz}), 2.73-2.83(\mathrm{~m}, 1 \mathrm{H}$, diazep.), 2.92 (t, 1H, diazep. J = 4.4 Hz), 3.29 (m, 2H, diazep.), 3.59 (s, 1H, Ph-CHH), 3.71 (s, 1H, Ph$\mathrm{CH} H$ ), 3.97 (m, 2H, diazep.), 7.20-7.55 (m, 9H, arom.), 7.88 (m, 3H, arom.). 
${ }^{13} \mathrm{CNMR}\left(\mathrm{CDCl}_{3}, \delta, \mathrm{ppm}\right): 27.45,28.80,44.95,45.59,48.47,48.60,53.96,55.30,55.97,56.06,62.45$, $62.63,123.47,123.64,125.00,06,125.13,125.15,126.38,126.90,127.03,127.09,128.22,128.31$, $128.33,128.35,128.61,128.83,128.84,129.52,133.49,133.51,135.15,135.18,138.93,138.95,170.70$, 170.80. LRMS $\left(\mathrm{ESI}^{+}\right)$: required $\mathrm{m} / \mathrm{z} 345.2$, found $\mathrm{m} / \mathrm{z} 345.3[\mathrm{M}+\mathrm{H}]^{+}$; elemental analysis calcd $(\%)$ for $\mathrm{C}_{23} \mathrm{H}_{24} \mathrm{~N}_{2} \mathrm{O}$ : C 80.20, H 7.02, N 8.13; found: C 80.55, H 7.30, N 8.25.

\section{(4-Benzyl-1,4-diazepan-1-yl)(phenyl)methanone (2g)}

Yellow oil; yield: $97 \%$; I.R. (nujol, $\left.\mathrm{cm}^{-1}\right): 1629 ;{ }^{1} \mathrm{HNMR}\left(\mathrm{CDCl}_{3}, \delta\right.$, ppm): 1.79 (m br 1H, diazep.), 1.99 $(\mathrm{q}, 1 \mathrm{H}$, diazep. $\mathrm{J}=4.8 \mathrm{~Hz}), 2.59(\mathrm{t}, 1 \mathrm{H}$, diazep. $\mathrm{J}=4.0 \mathrm{~Hz}), 2.63(\mathrm{t}, 1 \mathrm{H}$, diazep. $\mathrm{J}=4.8 \mathrm{~Hz}), 2.74(\mathrm{t}, 1 \mathrm{H}$, diazep. $\mathrm{J}=4.8 \mathrm{~Hz}), 2.82(\mathrm{t}, 1 \mathrm{H}$, diazep. $\mathrm{J}=4.0 \mathrm{~Hz}), 3.46(\mathrm{t}, 2 \mathrm{H}$, diazep. $\mathrm{J}=4.8 \mathrm{~Hz}), 3.62(\mathrm{~s}, 1 \mathrm{H}, \mathrm{Ph}-$ $\mathrm{CHH}), 3.68(\mathrm{~s}, 1 \mathrm{H}, \mathrm{Ph}-\mathrm{CH} H), 3.80$ (t, 2H, diazep. $\mathrm{J}=4.8 \mathrm{~Hz}), 7.20-7.40$ (m, 10H, arom.).

${ }^{13} \mathrm{CNMR}\left(\mathrm{CDCl}_{3}, \delta, \mathrm{ppm}\right): 27.04,28.93,45.47,48.78,49.86,54.05,54.95,55.95,56.21,62.36,62.56$, $126.61,126.66,127.10,128.28,128.31,128.39,128.70,128.84,128.88,129.17,129.25,130.56,134.53$, 137.06, 171.61. LRMS (ESI ${ }^{+}$): required $\mathrm{m} / z$ 295.2, found $\mathrm{m} / z .295 .0[\mathrm{M}+\mathrm{H}]^{+}$; elemental analysis calcd (\%) for $\mathrm{C}_{19} \mathrm{H}_{22} \mathrm{~N}_{2} \mathrm{O}$ : C 77.52, H 7.53, N 9.52; found: C 77.13, H 7.40, N 9.21.

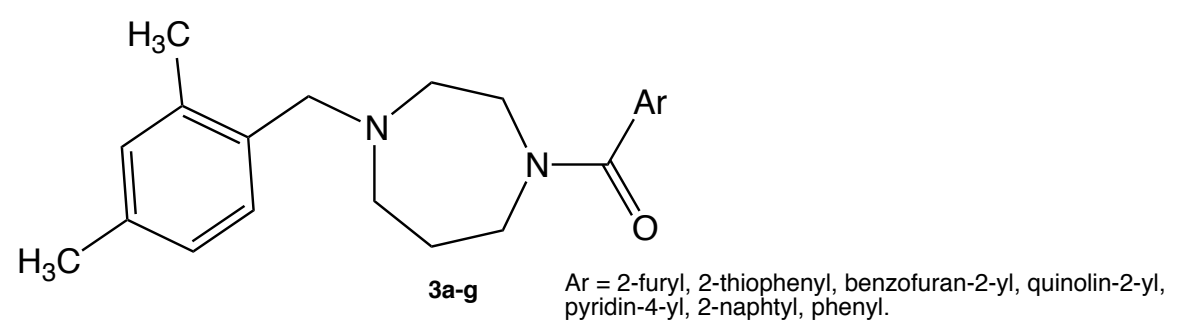

\subsubsection{General synthesis of final compounds 3a-g}

A solution of (1,4-diazepan-1-yl)(furan-2-yl)methanone $\mathbf{5 a} \quad(150 \quad \mathrm{mg}, \quad 0.77 \quad \mathrm{mmol})$, 2,4dimetylbenzaldehyde (100 mg, $0.77 \mathrm{mmol})$ in $20 \mathrm{~mL}$ of $\mathrm{CH}_{2} \mathrm{Cl}_{2}$ was stirred for $2 \mathrm{~h}$ at $\mathrm{rt}$. A slight excess of $\mathrm{NaCNBH}_{3}$ (70 mg, $1.16 \mathrm{mmol}$ ) was added and the mixture was left to stir overnight. The organic solution was then extracted with distilled water $(2 \times 25 \mathrm{~mL})$ and brine $(1 \times 25 \mathrm{~mL})$. The collected organic layer was dried $\left(\mathrm{Na}_{2} \mathrm{SO}_{4}\right)$, filtered and concentrated under vacuum and the residue was purified by DCVC.

\section{(4-(2,4-Dimethylbenzyl)-1,4-diazepan-1-yl)(furan-2-yl)methanone (3a)}

Pale yellow oil; yield: $35 \%$ (DCVC, $\mathrm{CH}_{2} \mathrm{Cl}_{2} 100$ then $\mathrm{CH}_{2} \mathrm{Cl}_{2} / \mathrm{EtOH}$ 95:5); I.R. (nujol, $\mathrm{cm}^{-1}$ ): 1607; ${ }^{1} \mathrm{HNMR}\left(\mathrm{CDCl}_{3}, \delta, \mathrm{ppm}\right): 1.93(\mathrm{q}, 2 \mathrm{H}$, diazep. J = 5.6, $6.0 \mathrm{~Hz}), 2.29\left(\mathrm{~s}, 3 \mathrm{H}, \mathrm{CH}_{3}\right.$.), $2.31\left(\mathrm{~s}, 3 \mathrm{H}, \mathrm{CH}_{3}\right.$.), $2.64\left(\mathrm{~m}\right.$ br $2 \mathrm{H}$, diazep.), $2.76(\mathrm{t}, 2 \mathrm{H}$, diazep. $\mathrm{J}=4.8 \mathrm{~Hz}), 3.54\left(\mathrm{~s}, 2 \mathrm{H}, \mathrm{Ph}_{-} \mathrm{CH}_{2}\right), 3.72(\mathrm{t}, 2 \mathrm{H}$, diazep. $\mathrm{J}=$ $6.0 \mathrm{~Hz}), 3.81$ (m, 2H, diazep.), 6.46 (br, $1 \mathrm{H}$, fur.), $6.97(\mathrm{~m}, 3 \mathrm{H}$, arom. $\mathrm{Ph}), 7.13(1 \mathrm{H}$, fur. $\mathrm{J}=6.0 \mathrm{~Hz})$, 7.45 (d br, 1H, fur. J = 13.6 Hz). ${ }^{13} \mathrm{CNMR}\left(\mathrm{CDCl}_{3}, \delta\right.$, ppm): 19.13, 20.97, 27.03, 28.45, 28.92, 46.01, 46.16, 47.85, 48.59, 54.10, 54.20, 56.60, 60.08, 63.31, 111.13, 116.03, 126.12, 126.54, 127.82, 129.71, 131.13, 131.18, 133.84, 135.63, 137.34, 143.60, 143.72, 148.37, 160.27. LRMS (ESI $\left.{ }^{+}\right)$required $\mathrm{m} / z$ 313.2, found $m / z 313.2[\mathrm{M}+\mathrm{H}]^{+}$; elemental analysis calcd $(\%)$ for $\mathrm{C}_{19} \mathrm{H}_{24} \mathrm{~N}_{2} \mathrm{O}_{2}$ : C 73.05, $\mathrm{H} \mathrm{7.74,} \mathrm{N}$ 8.97; found: C 72.88, H 7.55, N 8.76. 
(4-(2,4-Dimethylbenzyl)-1,4-diazepan-1-yl)(thiophen-2-yl)methanone (3b)

Pale yellow oil; yield: $37 \%$ (DCVC, $\mathrm{CH}_{2} \mathrm{Cl}_{2} 100$ then $\mathrm{CH}_{2} \mathrm{Cl}_{2} / \mathrm{EtOH}$ 95:5); I.R. (nujol, $\mathrm{cm}^{-1}$ ): 1606; ${ }^{1} \mathrm{HNMR}\left(\mathrm{CDCl}_{3}, \delta\right.$, ppm): 1.92 (m br $2 \mathrm{H}$, diazep.), 2.30 (s, 3H, $\mathrm{CH}_{3}$.), 2.32 (s, 3H, $\mathrm{CH}_{3}$.), 2.72 (br 4H, diazep.), 3.54 (s, 2H, Ph- $\left.\mathrm{CH}_{2}\right), 3.75$ (m, 4H, diazep.), 6.97 (m, 3H, arom. $\mathrm{Ph}$ ), 7.12 (d br, 1H, thioph. $\mathrm{J}=$ $7.2 \mathrm{~Hz}$ ), 7.30 (br, $1 \mathrm{H}$, thioph.), 7.42 (d, $1 \mathrm{H}$, fur. $\mathrm{J}=5.2 \mathrm{~Hz}) .{ }^{13} \mathrm{CNMR}\left(\mathrm{CDCl}_{3}, \delta\right.$, ppm): 19.15, 20.98, 25.59, 27.17, 29.11, 29.69, 46.22, 46.72, 49.00, 49.08, 53.99, 55.75, 60.13, 126.13, 126.63, 128.53, 128.66, 128.70, 129.74, 131.21, 133.82, 136.67, 137.36, 164.39. LRMS (ESI $\left.{ }^{+}\right)$: required $\mathrm{m} / z .329 .2$, found $\mathrm{m} / \mathrm{z} 329.1[\mathrm{M}+\mathrm{H}]^{+}$; elemental analysis calcd (\%) for $\mathrm{C}_{19} \mathrm{H}_{24} \mathrm{~N}_{2} \mathrm{OS}$ : C 69.47, H 7.36, N 8.53; found: C $69.70, \mathrm{H} 7.65, \mathrm{~N} 8.23$.

\section{Benzofuran-2-yl(4-(2,4-dimethylbenzyl)-1,4-diazepan-1-yl)methanone (3c)}

Pale yellow oil; yield: $34 \%$ (DCVC, $\mathrm{CH}_{2} \mathrm{Cl}_{2} 100$ then $\mathrm{CH}_{2} \mathrm{Cl}_{2} / \mathrm{EtOH}$ 95:5); I.R. (nujol, cm ${ }^{-1}$ ): 1630; ${ }^{1} \mathrm{HNMR}\left(\mathrm{CDCl}_{3}, \delta, \mathrm{ppm}\right): 1.97(\mathrm{q}$ br, $2 \mathrm{H}$, diazep. J = 5.2, $6.0 \mathrm{~Hz}), 2.30\left(\mathrm{~s}, 3 \mathrm{H}, \mathrm{CH}_{3}\right.$.), $2.33\left(\mathrm{~s}, 3 \mathrm{H}, \mathrm{CH}_{3}\right.$.), 2.67 (m, 2H, diazep.), 2.80 (t, 2H, diazep. J = 5.2 Hz), $3.56\left(\mathrm{~s}, 2 \mathrm{H}, \mathrm{Ph}-\mathrm{CH}_{2}\right), 3.84$ (m, 4H, diazep.), 6.95 $(\mathrm{m}, 2 \mathrm{H}$, arom.), $7.14(\mathrm{t}, 1 \mathrm{H}$, arom. $\mathrm{J}=8.0 \mathrm{~Hz}), 7.28(\mathrm{~d}, 2 \mathrm{H}$, arom. $\mathrm{J}=7.6 \mathrm{~Hz}), 7.38(\mathrm{~m}, 1 \mathrm{H}$, arom.), 7.50 $(\mathrm{dd}, 1 \mathrm{H}$, arom. $\mathrm{J}=4.4,12.8 \mathrm{~Hz}), 7.64(\mathrm{t}, 1 \mathrm{H}$, arom. $\mathrm{J}=7.2 \mathrm{~Hz}) .{ }^{13} \mathrm{CNMR}\left(\mathrm{CDCl}_{3}, \delta, \mathrm{ppm}\right): 19.15,20.99$, 27.01, 29.09, 46.30, 46.97, 48.10, 48.96, 54.12, 54.84, 55.28, 56.48, 60.19, 111.47, 111.82, 122.19, $122.44,123.48,123.83,126.13,126.26,127.01,129.71,131.22,133.88,136.67,137.37,149.46,154.59$, 154.70, 161.01. LRMS $\left(\mathrm{ESI}^{+}\right)$: required $\mathrm{m} / \mathrm{z}$ 363.2, found $\mathrm{m} / \mathrm{z} 363.2[\mathrm{M}+\mathrm{H}]^{+}$; elemental analysis calcd (\%) for $\mathrm{C}_{23} \mathrm{H}_{26} \mathrm{~N}_{2} \mathrm{O}_{2}$ : C 76.21, H 7.23, N 7.73; found: C 75.90, H 7.15, N 7.50.

\section{(4-(2,4-dimethylbenzyl)-1,4-diazepan-1-yl)(quinolin-2-yl)methanone (3d)}

Pale yellow oil; yield: $36 \%$ (DCVC, $\mathrm{CH}_{2} \mathrm{Cl}_{2} 100$ then $\mathrm{CH}_{2} \mathrm{Cl}_{2} / \mathrm{EtOH}$ 95:5); I.R. (nujol, cm ${ }^{-1}$ ): 1626; ${ }^{1} \mathrm{HNMR}\left(\mathrm{CDCl}_{3}, \delta, \mathrm{ppm}\right): 1.83(\mathrm{q}, 1 \mathrm{H}$, diazep. $\mathrm{J}=6.0 \mathrm{~Hz}), 2.00(\mathrm{q}, 1 \mathrm{H}$, diazep. J = $6.0 \mathrm{~Hz}), 2.27-2.35$ (m, 6H, 2 x CH .) 2.68 (m, 2H, diazep.), 2.75 (t, 1H, diazep. J=5.2 Hz), $2.85(\mathrm{t}, 1 \mathrm{H}$, diazep. $\mathrm{J}=5.2 \mathrm{~Hz})$, 3.54 (s, 1H, Ph-CHH), 3.59 (s, 1H, Ph-CHH), 3.65 (m, 2H, diazep.), 3.85 (m, 2H, diazep.), 6.99 (m, 2H, arom.), 7.14 (dd, $1 \mathrm{H}$, arom. $\mathrm{J}=8.0,31.2 \mathrm{~Hz}$ ), 7.58 (m, 1H, arom.), 7.67 (dd, 1H, arom. J = 6.8, 8.4 Hz), $7.74(\mathrm{~m}, 1 \mathrm{H}$, arom.), 7.84 (m, 1H, arom.), 8.08 (td, 1H, arom. J = 1.2, $8.8 \mathrm{~Hz}), 8.23$ (t, 1H, arom. $\mathrm{J}=8.8$ $\mathrm{Hz}) .{ }^{13} \mathrm{CNMR}\left(\mathrm{CDCl}_{3}, \delta, \mathrm{ppm}\right): 19.15,19.18,20.95,20.99,26.95,28.94,45.89,46.70,54.08,54.73$, 55.32 , 56.40, 60.10, 60.16, 63.37, 120.38, 120.52, 126.08, 126.13, 126.56, 127.37, 127.60, 127.62, 127.87, 127.91, 129.66, 129.70, 129.74, 129.95, 131.17, 131.19, 136.59, 137.03, 137.33, 137.36, 137.44, 146.61, 146.67, 154.58, 169.03, 169.11. LRMS $\left(\mathrm{ESI}^{+}\right)$: required $\mathrm{m} / \mathrm{z} 374.2$, found $\mathrm{m} / \mathrm{z} 374.3[\mathrm{M}+\mathrm{H}]^{+}$; elemental analysis calcd (\%) for $\mathrm{C}_{24} \mathrm{H}_{27} \mathrm{~N}_{3} \mathrm{O}$ : C 77.18, H 7.29, N 11.25; found: C 77.20, H 7.29, N 11.35.

\section{(4-(2,4-dimethylbenzyl)-1,4-diazepan-1-yl)(pyridin-4-yl)methanone (3e)}

Pale yellow oil; yield: $29 \%$ (DCVC, $\mathrm{CH}_{2} \mathrm{Cl}_{2} 100$ then $\mathrm{CH}_{2} \mathrm{Cl}_{2} / \mathrm{EtOH}$ 95:5); I.R. (nujol, cm ${ }^{-1}$ ): 1629; ${ }^{1} \mathrm{HNMR}\left(\mathrm{CDCl}_{3}, \delta, \mathrm{ppm}\right): 1.67$ (m, 1H, diazep.), $1.87(\mathrm{~m}, 1 \mathrm{H}$, diazep. J = 6.0 Hz), 2.22-2.27 (m, 6H, $2 \mathrm{xCH}_{3}$.), $2.48(\mathrm{t}, 1 \mathrm{H}$, diazep. $\mathrm{J}=5.2 \mathrm{~Hz}), 2.53(\mathrm{t}, 1 \mathrm{H}$, diazep. $\mathrm{J}=5.6 \mathrm{~Hz}), 2.64(\mathrm{t}, 1 \mathrm{H}$, diazep. $\mathrm{J}=5.6 \mathrm{~Hz})$, $2.71(\mathrm{t}, 1 \mathrm{H}$, diazep. $\mathrm{J}=5.68 \mathrm{~Hz}), 3.27(\mathrm{t}, 1 \mathrm{H}$, diazep. $\mathrm{J}=5.6 \mathrm{~Hz}), 3.31(\mathrm{t}, 1 \mathrm{H}$, diazep. $\mathrm{J}=6.0 \mathrm{~Hz}), 3.45$ (s, 1H, Ph-CHH), 3.49 (s, 1H, Ph-CHH), 3.69 (m, 2H, diazep.), 6.86 (t, 1H, arom. J = 7.6 Hz), 6.90 (d, $1 \mathrm{H}$, arom. $\mathrm{J}=7.2 \mathrm{~Hz}), 7.03$ (m, 1H, arom.) 7.14 (d, 1H, arom. pyr. J = $6.0 \mathrm{~Hz}), 7.20$ (d, 1H, arom. pyr. J $=6.0 \mathrm{~Hz}), 8.54(\mathrm{~d}, 1 \mathrm{H}$, arom. pyr. $\mathrm{J}=6.0 \mathrm{~Hz}), 8.61(\mathrm{~d}, 1 \mathrm{H}$, arom. pyr. $\mathrm{J}=6.0 \mathrm{~Hz}) .{ }^{13} \mathrm{CNMR}\left(\mathrm{CDCl}_{3}, \delta\right.$, ppm): 18.11, 18.15, 19.95, 19.98, 26.05, 27.97, 28.67, 44.43, 45.17, 47.59, 48.65, 52.83, 53.57, 54.63, 
$54.92,59.36,59.40,108.98,119.89,119.97,152.14,128.70,128.74,130.23,130.26,135.84,136.29$, 143.52, 149.13, 149.19, 167.83, 167.90. LRMS $\left(\mathrm{ESI}^{+}\right)$: required $\mathrm{m} / \mathrm{z} 324.2$, found $\mathrm{m} / \mathrm{z} 324.2[\mathrm{M}+\mathrm{H}]^{+}$; elemental analysis calcd (\%) for $\mathrm{C}_{20} \mathrm{H}_{25} \mathrm{~N}_{3} \mathrm{O}$ : C 74.27, H 7.79, N 12.99; found: C 74.10, H 7.92, N 12.75.

\section{(4-(2,4-Dimethylbenzyl)-1,4-diazepan-1-yl)(naphthalen-1-yl)methanone (3f)}

Pale yellow oil; yield: $40 \%$ (DCVC, $\mathrm{CH}_{2} \mathrm{Cl}_{2} 100$ then $\mathrm{CH}_{2} \mathrm{Cl}_{2}$ /EtOH 95:5); I.R. (nujol, $\mathrm{cm}^{-1}$ ): 1626; ${ }^{1} \mathrm{HNMR}\left(\mathrm{CDCl}_{3}, \delta, \mathrm{ppm}\right): 2.03$ (m, 1H, diazep.), 2.25-2.36 (m, 7H, $2 \times \mathrm{CH}_{3}$ and diazep.), $2.44(\mathrm{~m}, 1 \mathrm{H}$, diazep.), $2.58(\mathrm{~m}, 1 \mathrm{H}$, diazep.), 2.77 (m, 1H, diazep.), $2.88(\mathrm{t}, 1 \mathrm{H}$, diazep. $\mathrm{J}=4.4 \mathrm{~Hz}), 3.26(\mathrm{t}, 2 \mathrm{H}$, diazep. $\mathrm{J}=5.6 \mathrm{~Hz}), 3.48(\mathrm{~s}, 1 \mathrm{H}, \mathrm{Ph}-\mathrm{CHH}), 3.59(\mathrm{~s}, 1 \mathrm{H}, \mathrm{Ph}-\mathrm{CH} H), 3.95$ (m, 2H, diazep.), 6.99 (m, 2H, arom.), $7.19(\mathrm{dd}, 1 \mathrm{H}$, arom. $\mathrm{J}=7.6,16.8 \mathrm{~Hz}), 7.48(\mathrm{~m}, 2 \mathrm{H}$, arom.), $7.52(\mathrm{~m}, 2 \mathrm{H}$, arom.), $7.74(\mathrm{~m}, 1 \mathrm{H}$, arom.), 7.85 (m, 2H, arom.). ${ }^{13} \mathrm{CNMR}\left(\mathrm{CDCl}_{3}, \delta, \mathrm{ppm}\right): 19.26,19.35,21.08,21.14,27.54,29.00,45.17,45.81$, $48.62,49.82,54.08,54.46,56.02,56.16,60.34,60.54,123.63,123.80,125.12,125.26,125.30,126.20$, $126.29,126.50,126.73,127.05,128.00,128.46,128.50,129.63,129.72,129.90,131.29,131.34,131.35$, 133.64, 133.96, 134.12, 135.31, 136.23, 136.76, 136.79, 137.36, 137.48, 170.84. LRMS (ESI $)$ : required $m / z$ 373.2, found $m / z 373.1[\mathrm{M}+\mathrm{H}]^{+}$; elemental analysis calcd (\%) for $\mathrm{C}_{25} \mathrm{H}_{28} \mathrm{~N}_{2} \mathrm{O}: \mathrm{C} 80.61, \mathrm{H} 7.58, \mathrm{~N}$ 7.52; found: C 80.65, H 7.65, N 7.77.

\section{(4-(2,4-dimethylbenzyl)-1,4-diazepan-1-yl)(phenyl)methanone (3g)}

Pale yellow oil; yield: $30 \%$ (DCVC, $\mathrm{CH}_{2} \mathrm{Cl}_{2} 100$ then $\mathrm{CH}_{2} \mathrm{Cl}_{2}$ /EtOH 95:5); I.R. (nujol, $\mathrm{cm}^{-1}$ ): 1625; ${ }^{1} \mathrm{HNMR}\left(\mathrm{CDCl}_{3}, \delta, \mathrm{ppm}\right): 1.74(\mathrm{~m}, 1 \mathrm{H}$, diazep.), $1.95(\mathrm{q}, 1 \mathrm{H}$, diazep. $\mathrm{J}=6.0 \mathrm{~Hz}), 2.28-2.38(\mathrm{~m}, 6 \mathrm{H}$, $2 \mathrm{xCH}_{3}$.), $2.55(\mathrm{t}, 1 \mathrm{H}$, diazep. $\mathrm{J}=4.8 \mathrm{~Hz}), 2.60(\mathrm{~m}, 1 \mathrm{H}$, diazep.), $2.71(\mathrm{t}, 1 \mathrm{H}$, diazep. $\mathrm{J}=5.6 \mathrm{~Hz}), 2.79(\mathrm{~m}$, $1 \mathrm{H}$ diazep.), 3.43 (m, 2H, diazep.), 3.51 (s, $1 \mathrm{H}, \mathrm{Ph}-\mathrm{CH} \mathrm{H}), 3.56$ (s, $1 \mathrm{H}, \mathrm{Ph}-\mathrm{CH} H), 3.78$ (m, 2H, diazep.), $6.93(\mathrm{~m}, 2 \mathrm{H}$, arom.), 7.11 (dd, $1 \mathrm{H}$, arom. $\mathrm{J}=7.2,32.8 \mathrm{~Hz}), 7.37\left(\mathrm{~m}, 5 \mathrm{H}\right.$, arom.). ${ }^{13} \mathrm{CNMR}\left(\mathrm{CDCl}_{3}, \delta\right.$, ppm): 19.26, 19.31, 21.10, 21.13, 27.23, 29.18, 45.64, 46.32, 49.00, 50.08, 54.02, 55.03, 56.02, 56.14, $60.29,60.48,126.23,126.27,126.74,126.79,128.49,128.57,129.27,129.36,129.80,129.91,131.34$, 136.81, 137.19, 137.48, 171.72. LRLRMS $\left(\mathrm{ESI}^{+}\right)$: required $\mathrm{m} / \mathrm{z} 323.2$, found $\mathrm{m} / \mathrm{z} 323.1[\mathrm{M}+\mathrm{H}]^{+}$; elemental analysis calcd (\%) for $\mathrm{C}_{21} \mathrm{H}_{26} \mathrm{~N}_{2} \mathrm{O}$ : C 78.22, $\mathrm{H}$ 8.13, $\mathrm{N}$ 8.69; found: C 77.95, H 8.02, N 8.35. 


\subsubsection{NMR spectral data of the final compounds 2a-g and 3a-g.}
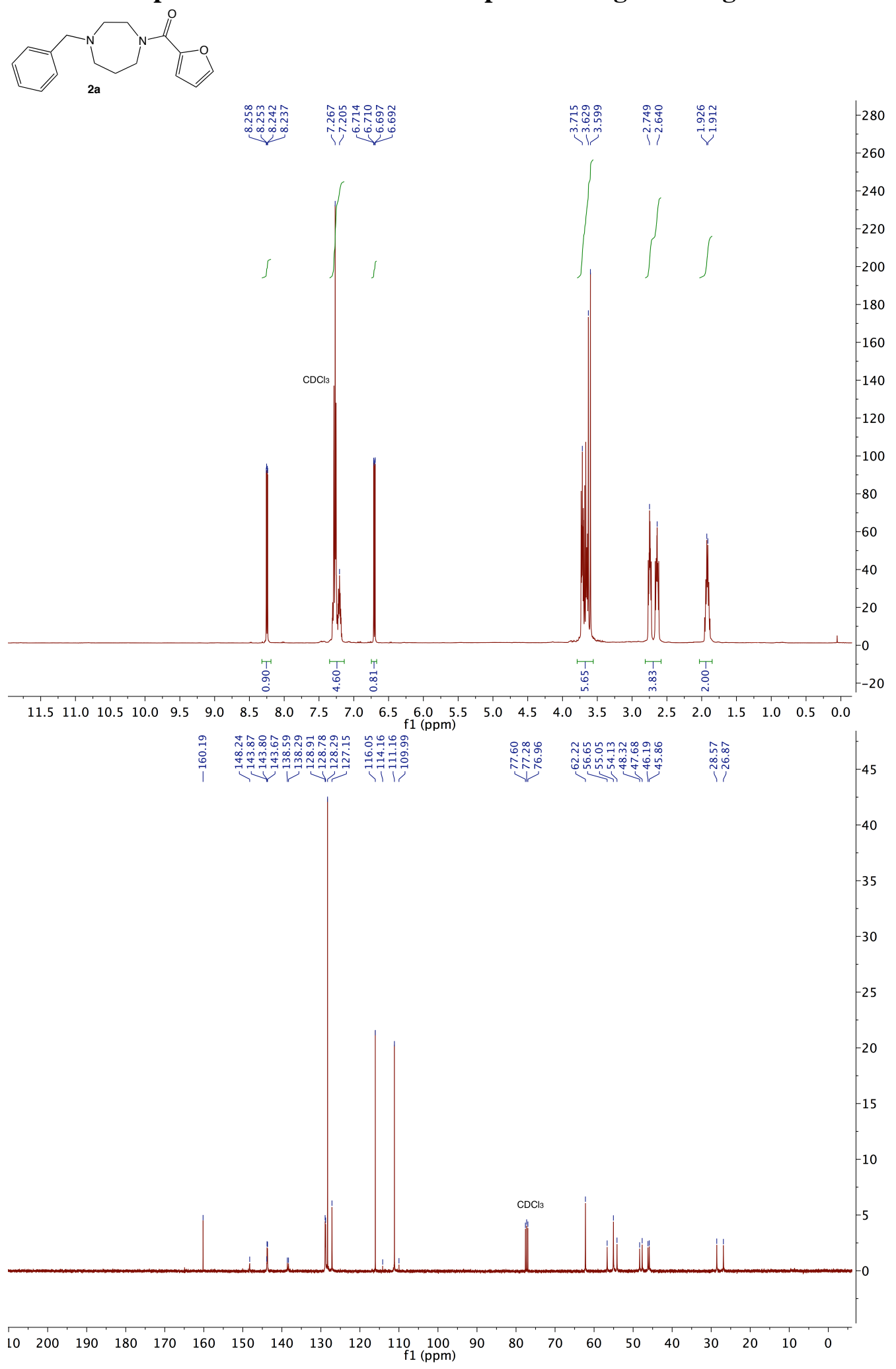

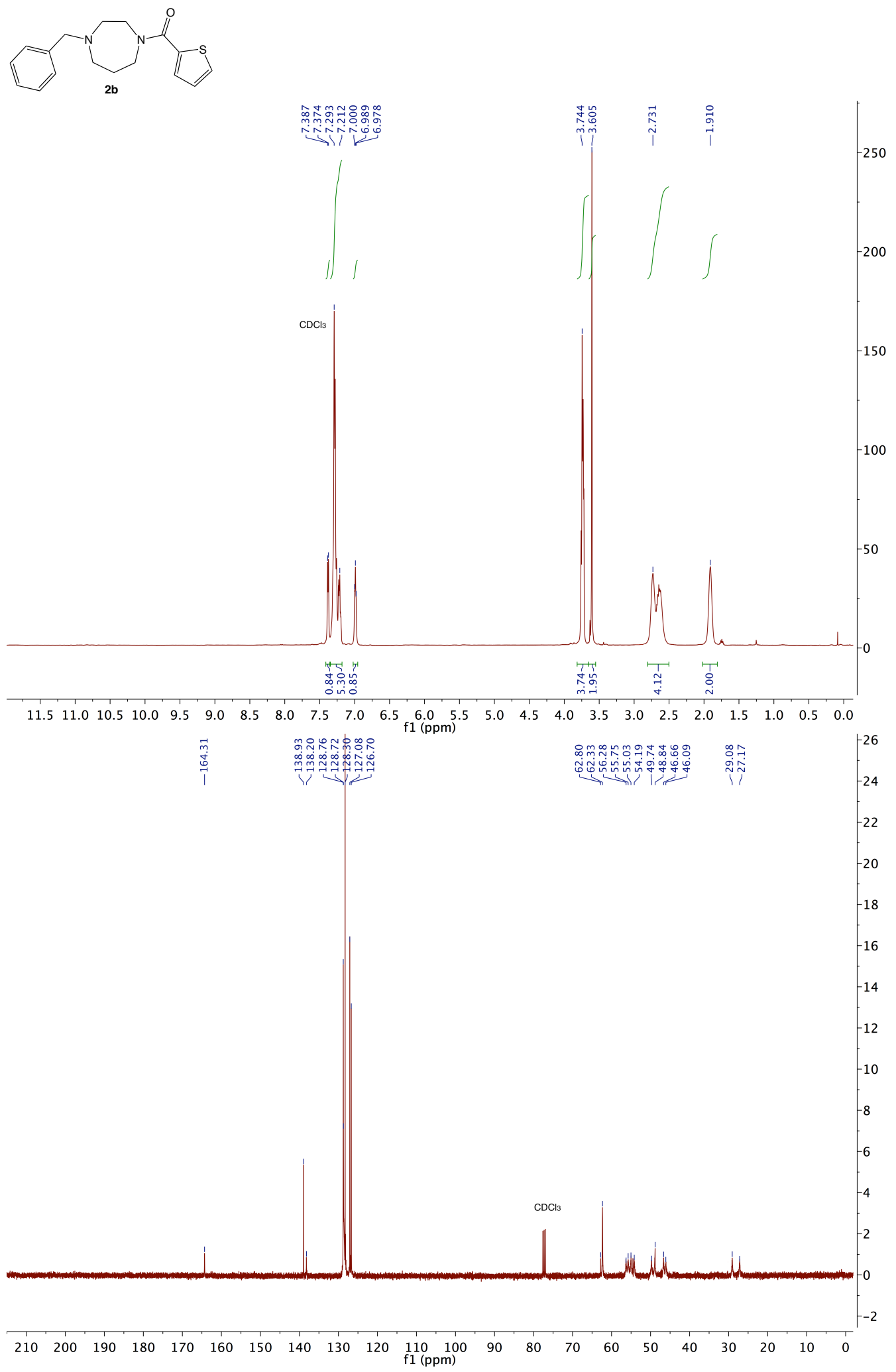


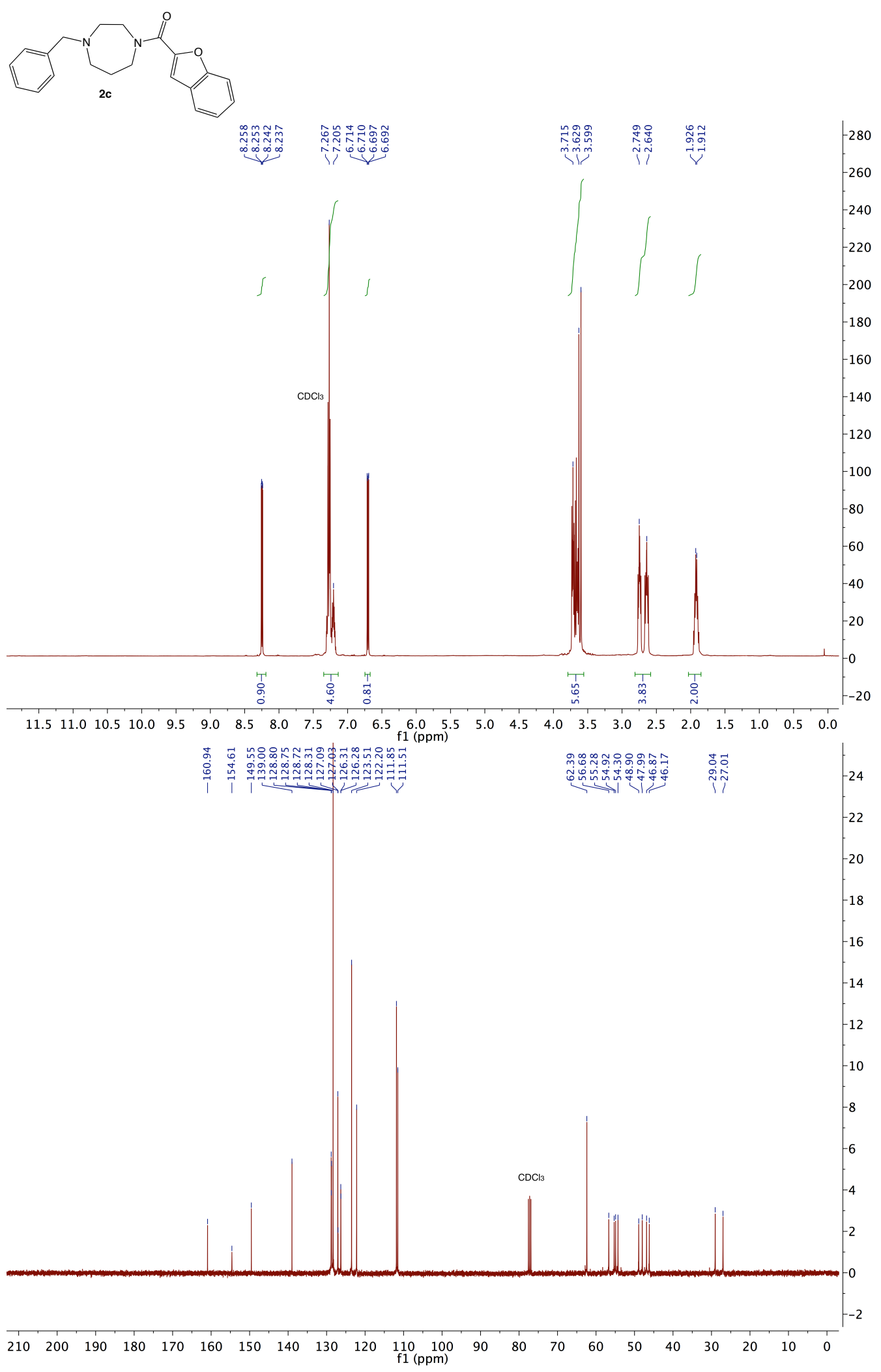



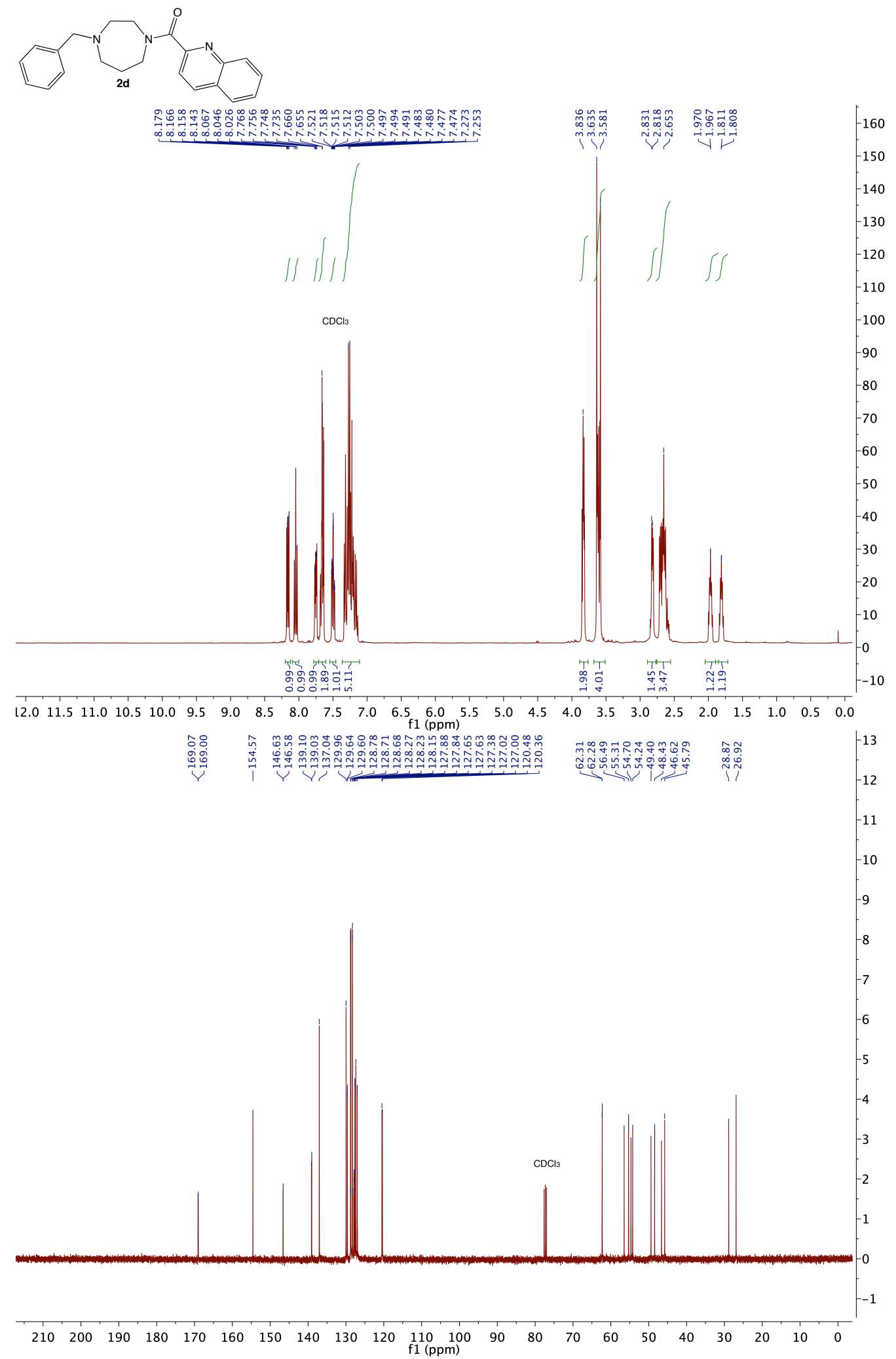


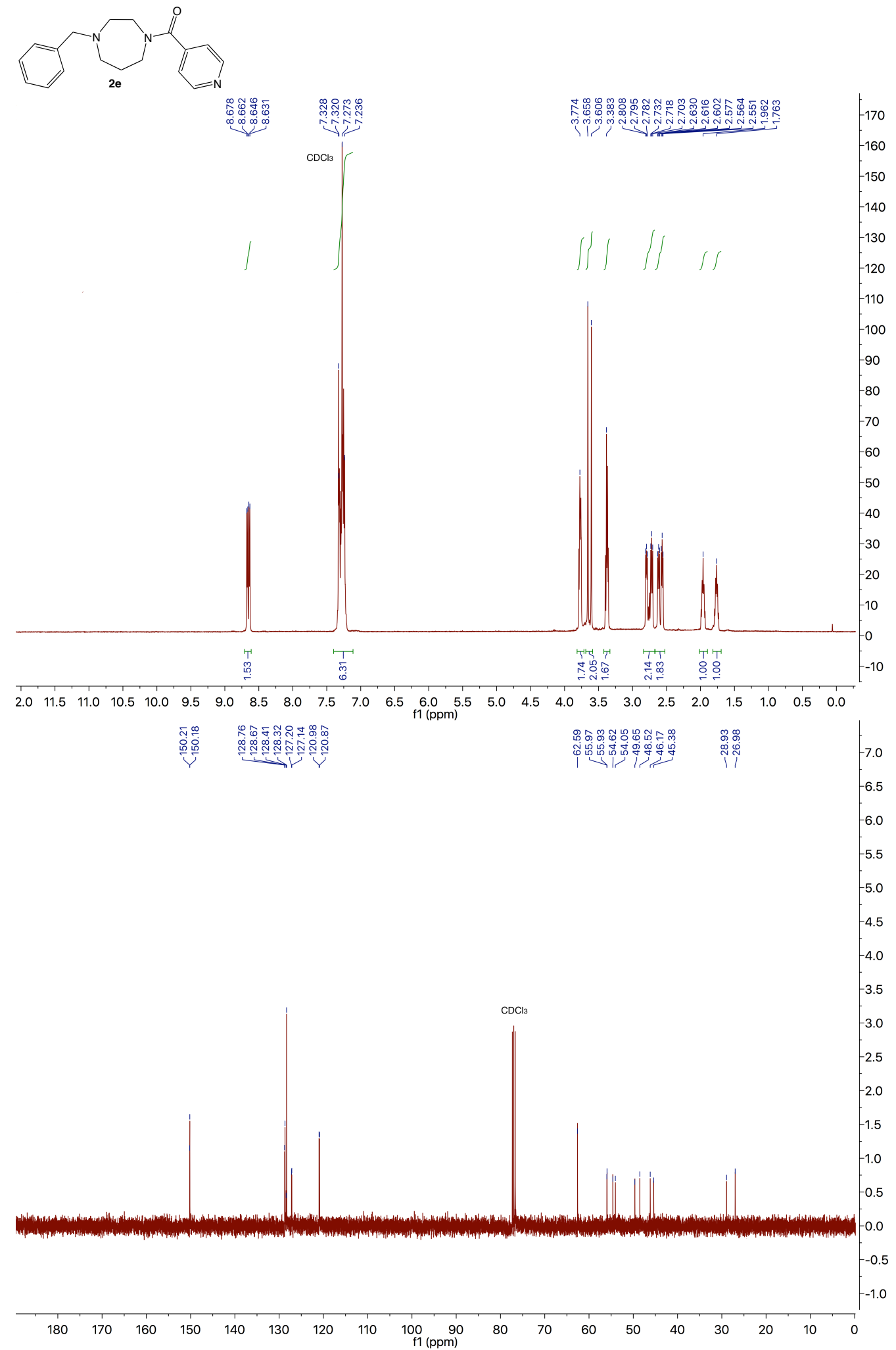




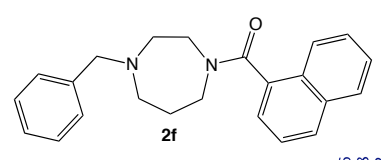

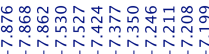
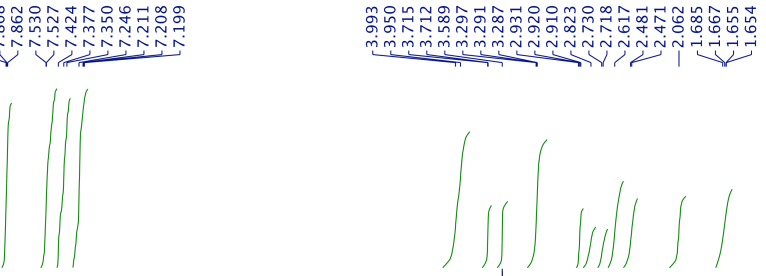

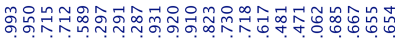

$-340$

$-320$

$-300$

$-280$

$-260$

$-240$

$-220$

$-200$
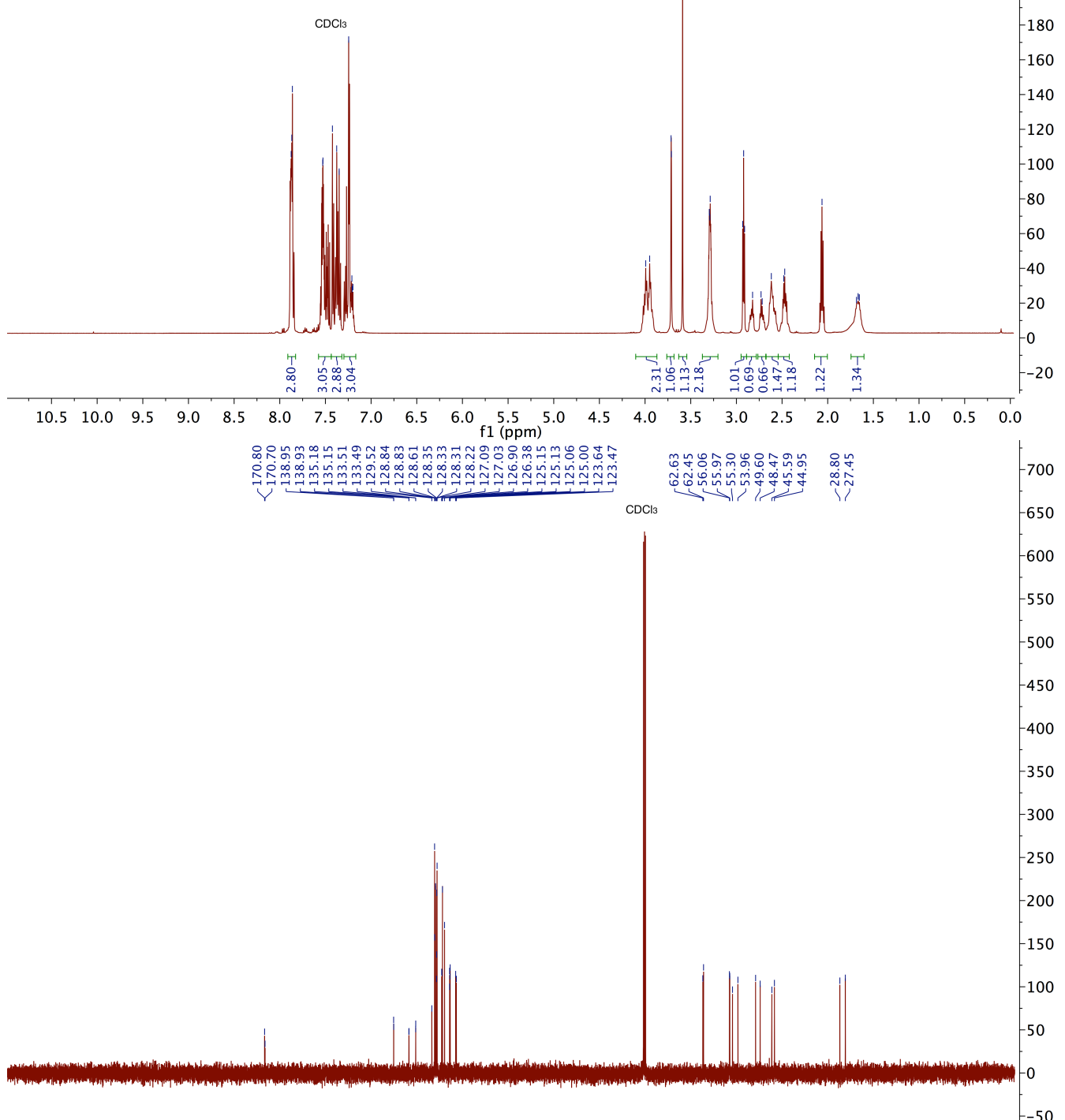

$\begin{array}{llllllllllllllllllllllllll}230 & 220 & 210 & 200 & 190 & 180 & 170 & 160 & 150 & 140 & 130 & 120 & 110 & 100 & 90 & 80 & 70 & 60 & 50 & 40 & 30 & 20 & 10 & 0 & -10\end{array}$ 

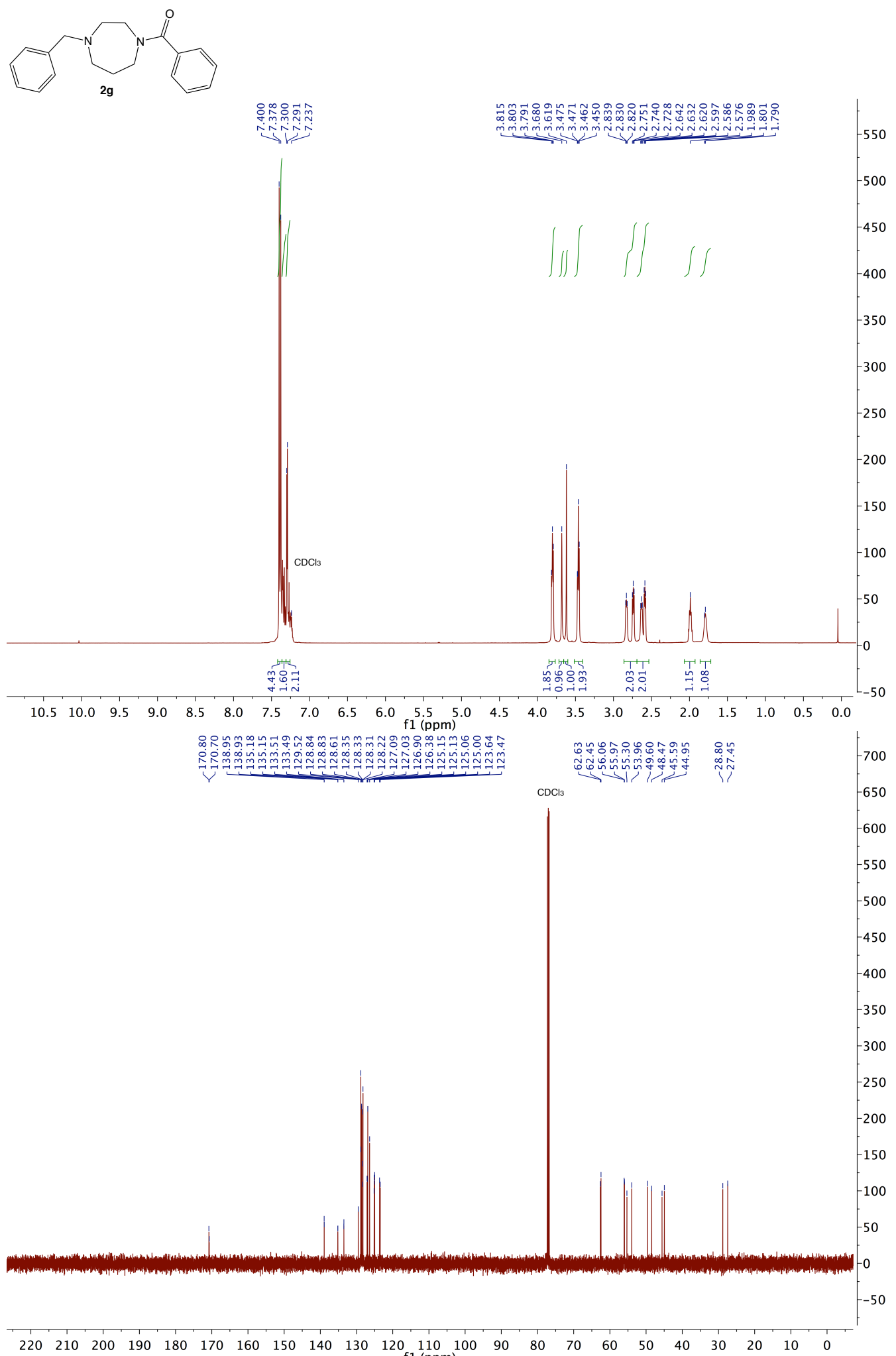

$\begin{array}{lllllllllllllllllllllll}220 & 210 & 200 & 190 & 180 & 170 & 160 & 150 & 140 & 130 & 120 \\ \mathrm{f} 1(\mathrm{ppm}) & 100 & 90 & 80 & 70 & 60 & 50 & 40 & 30 & 20 & 10 & 0\end{array}$ 

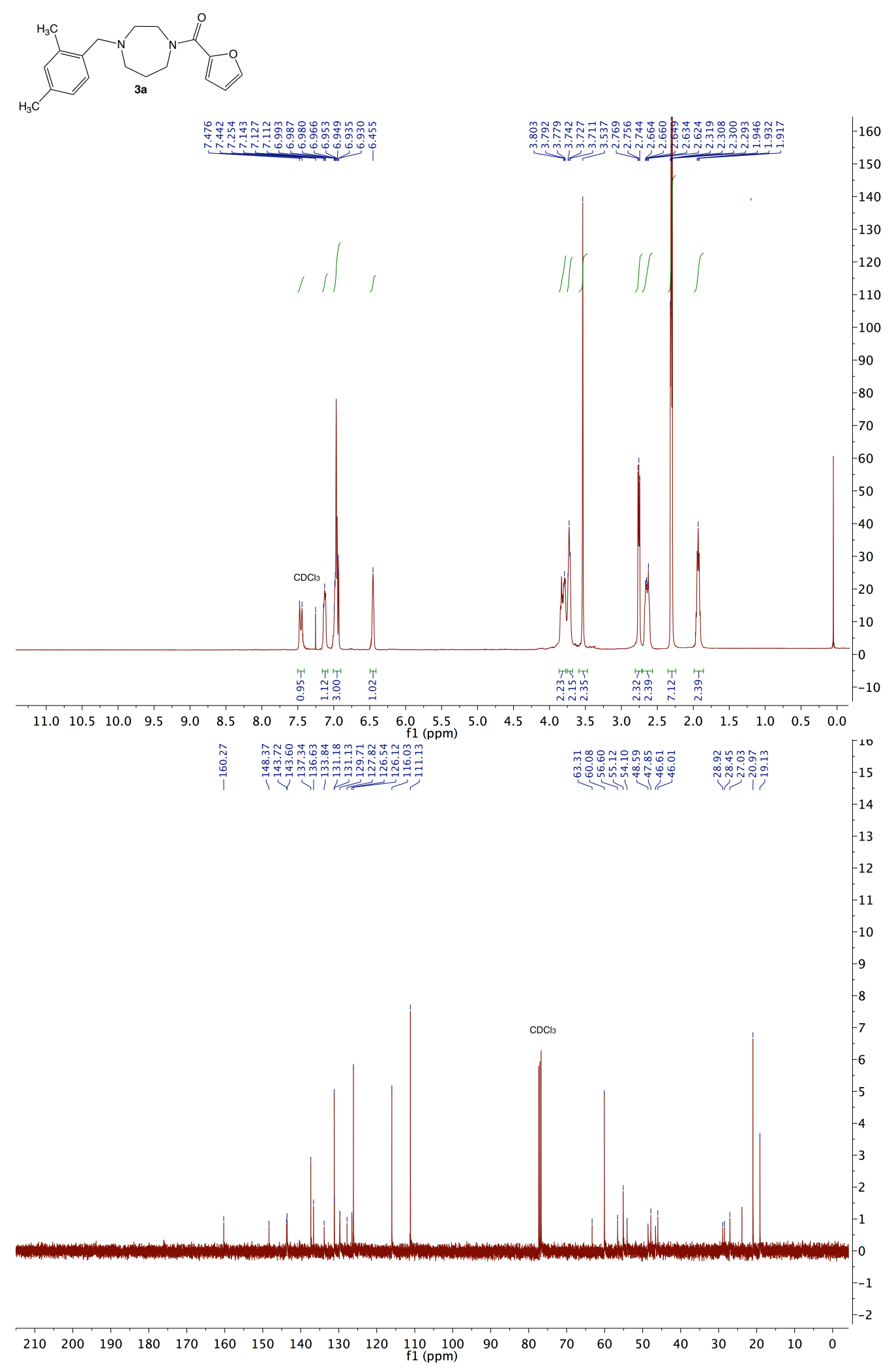

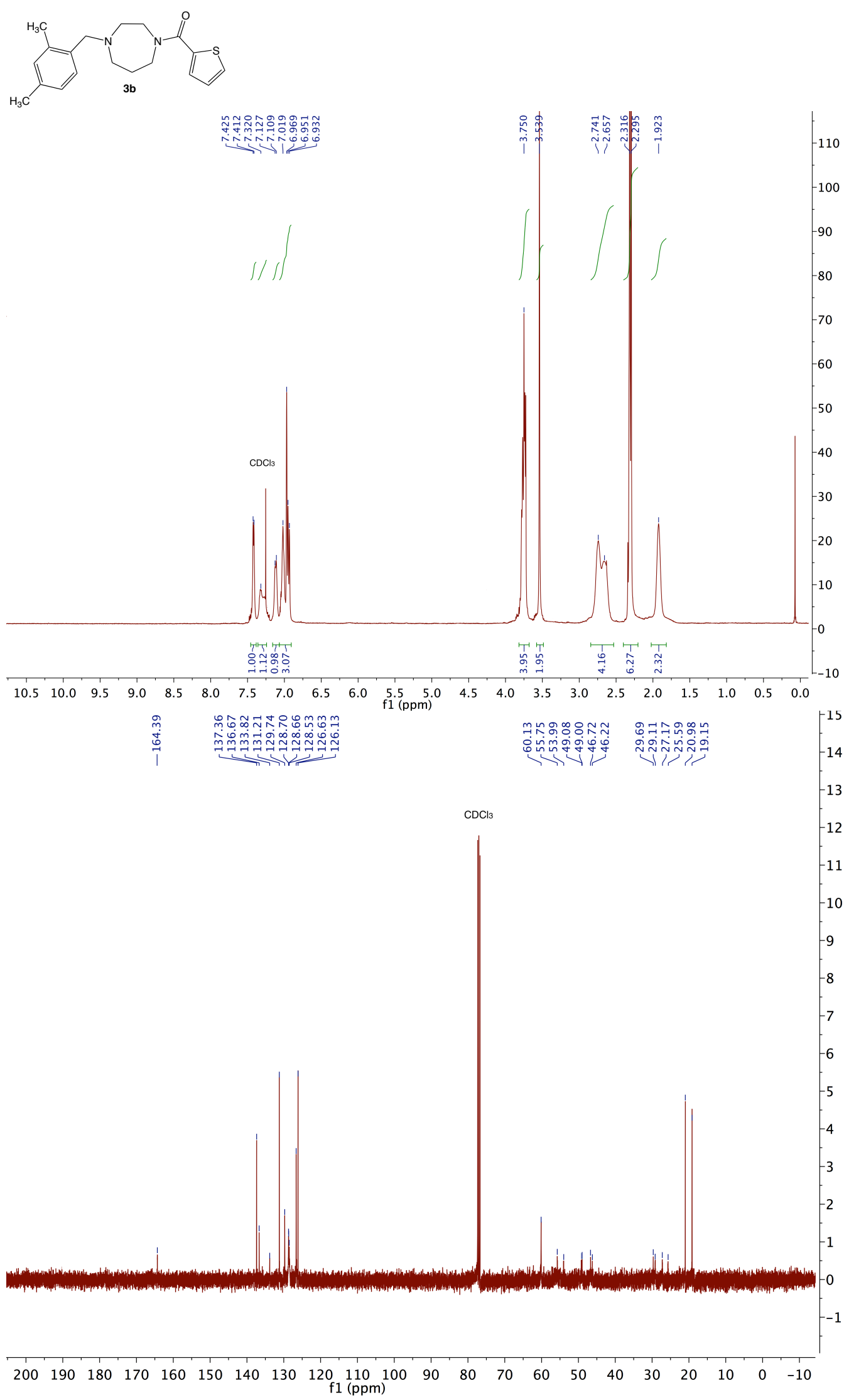

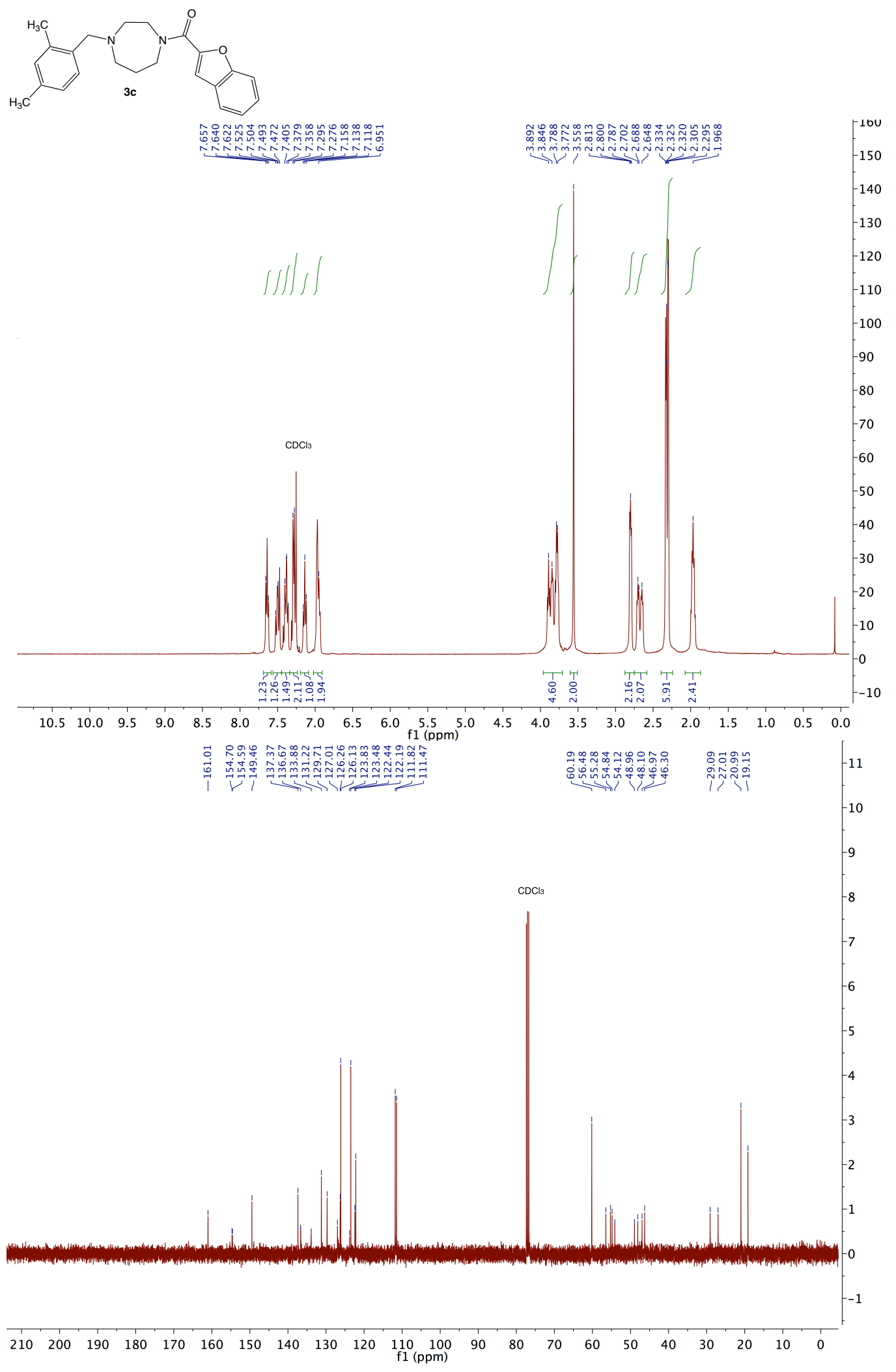


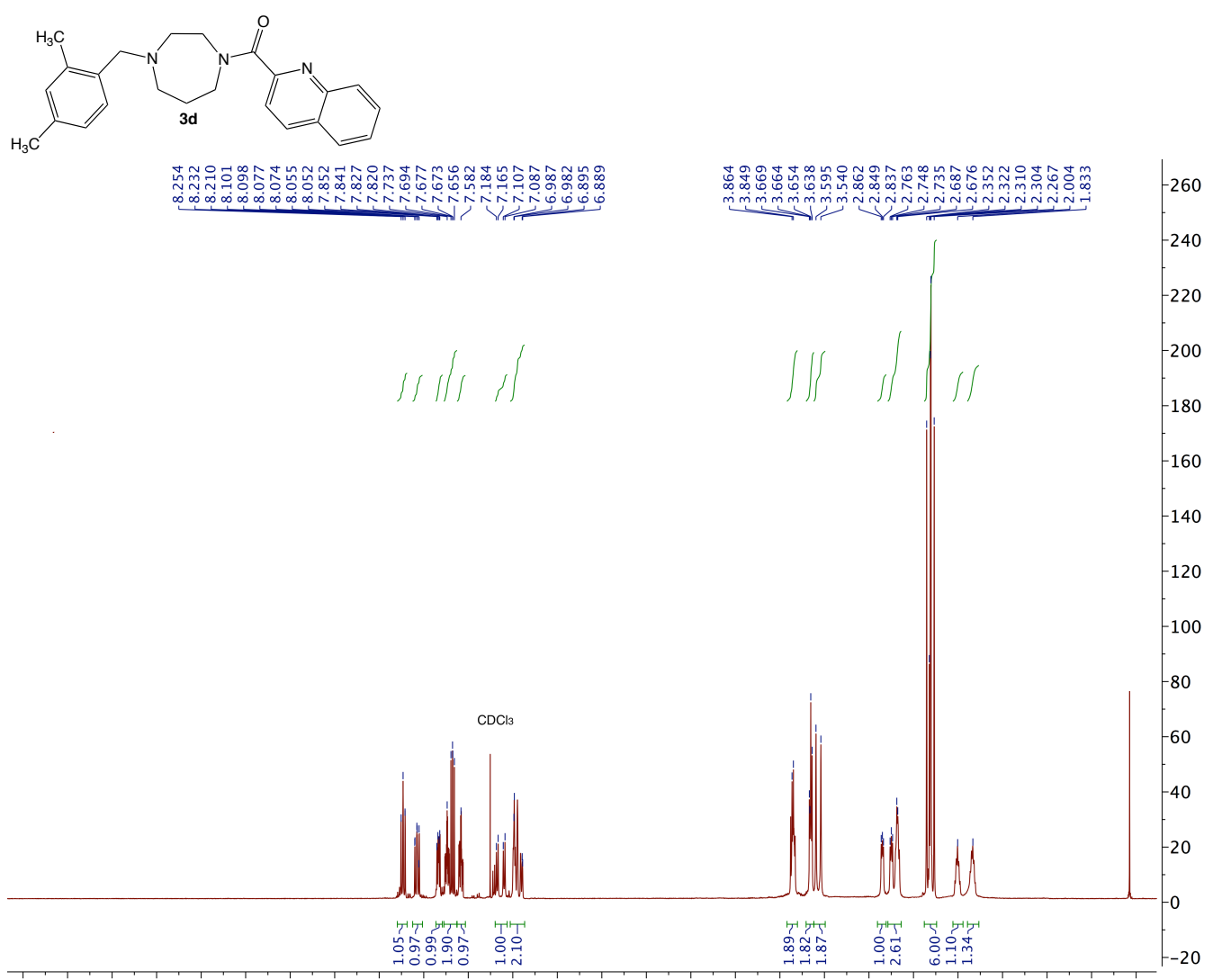

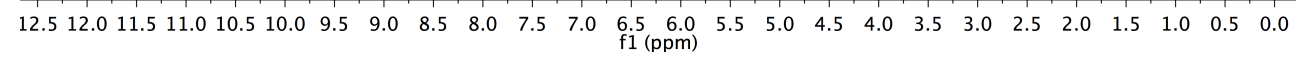
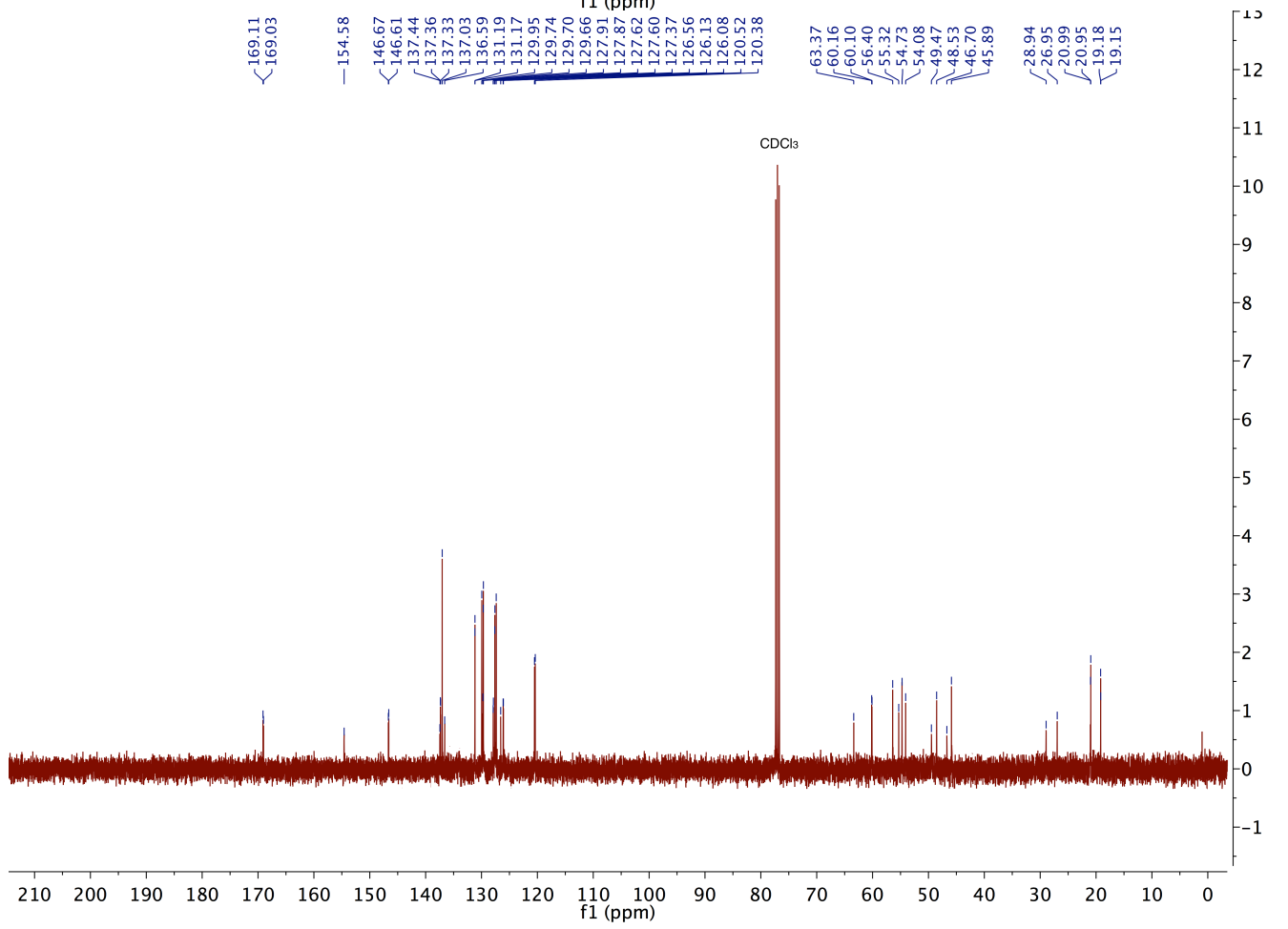


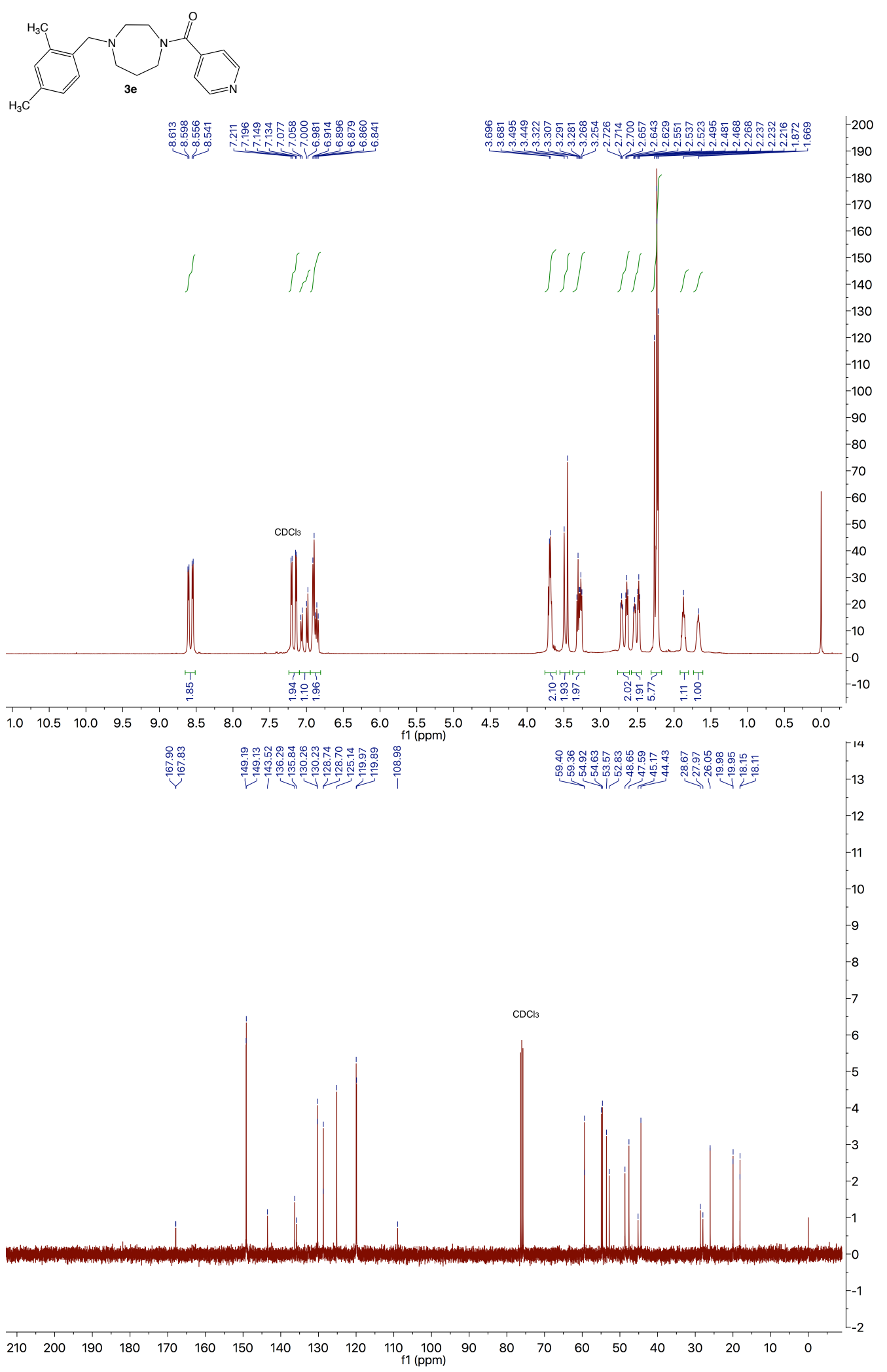




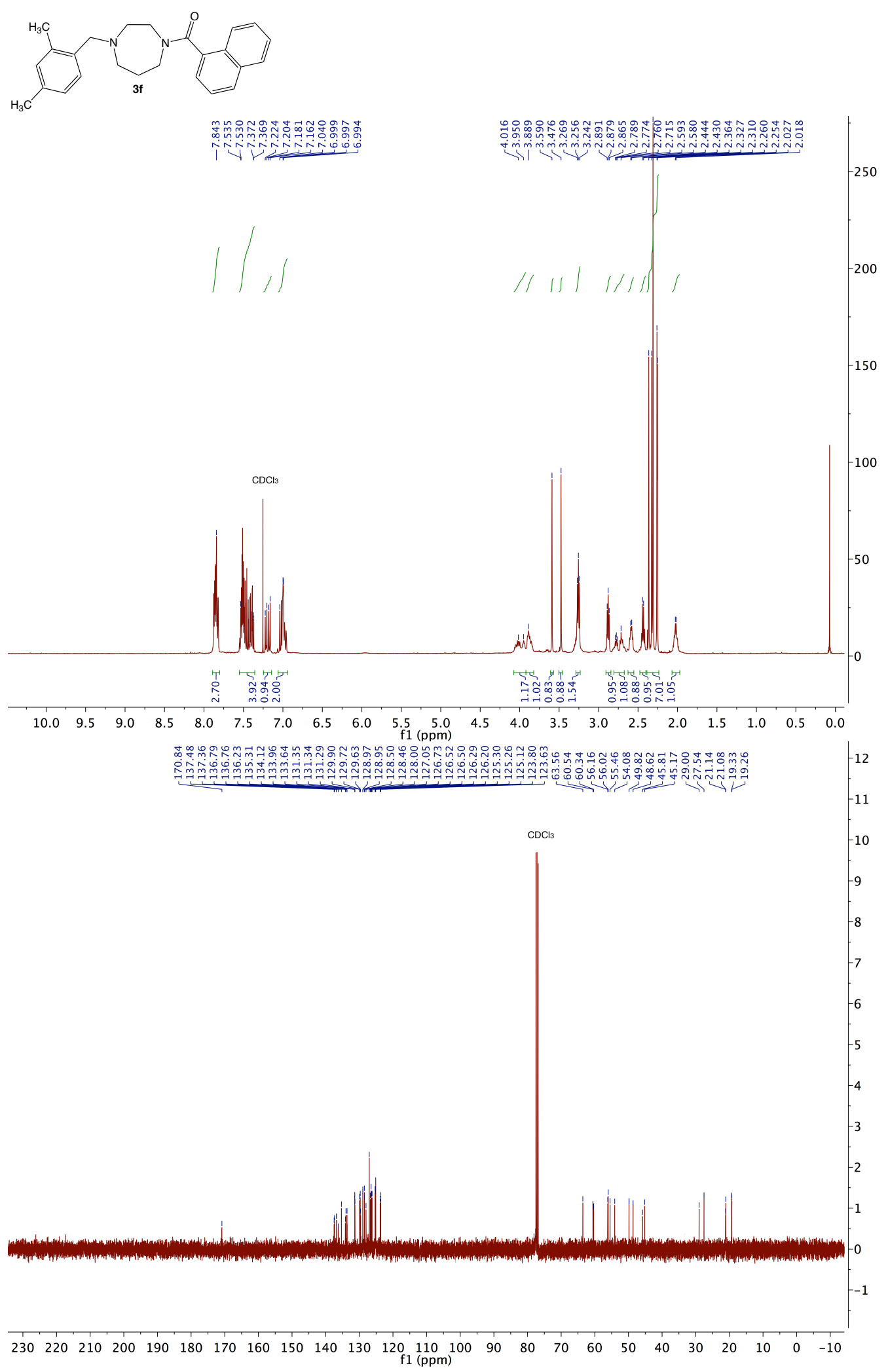




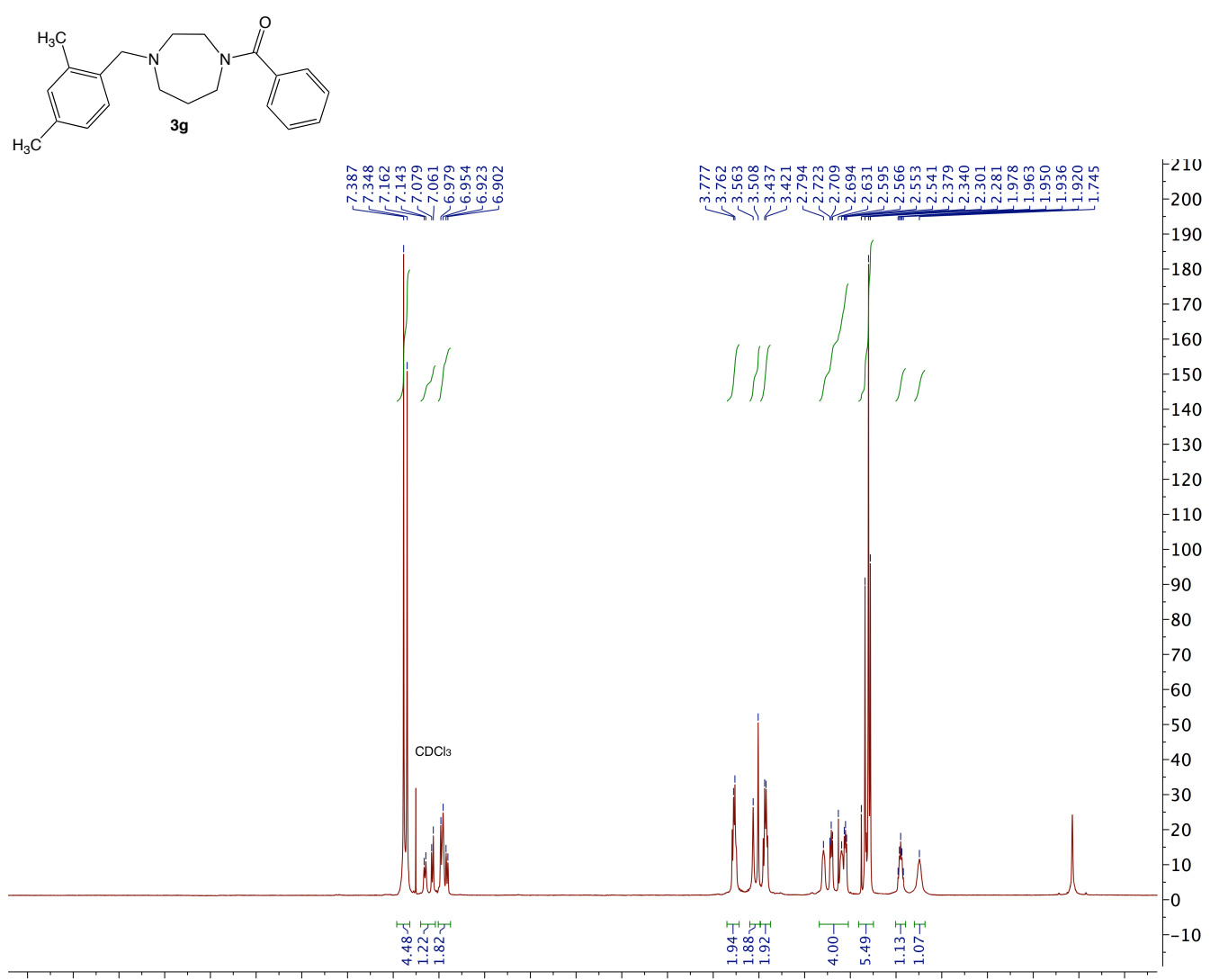

$\begin{array}{lllllllllllllllllllllllllllllll}11.5 & 11.0 & 10.5 & 10.0 & 9.5 & 9.0 & 8.5 & 8.0 & 7.5 & 7.0 & 6.5 & 6.0 & 5.5 & 5.0 & 4.5 & 4.0 & 3.5 & 3.0 & 2.5 & 2.0 & 1.5 & 1.0 & 0.5 & 0.0 & -0.5\end{array}$ 苒

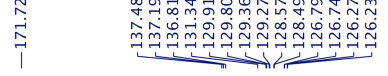

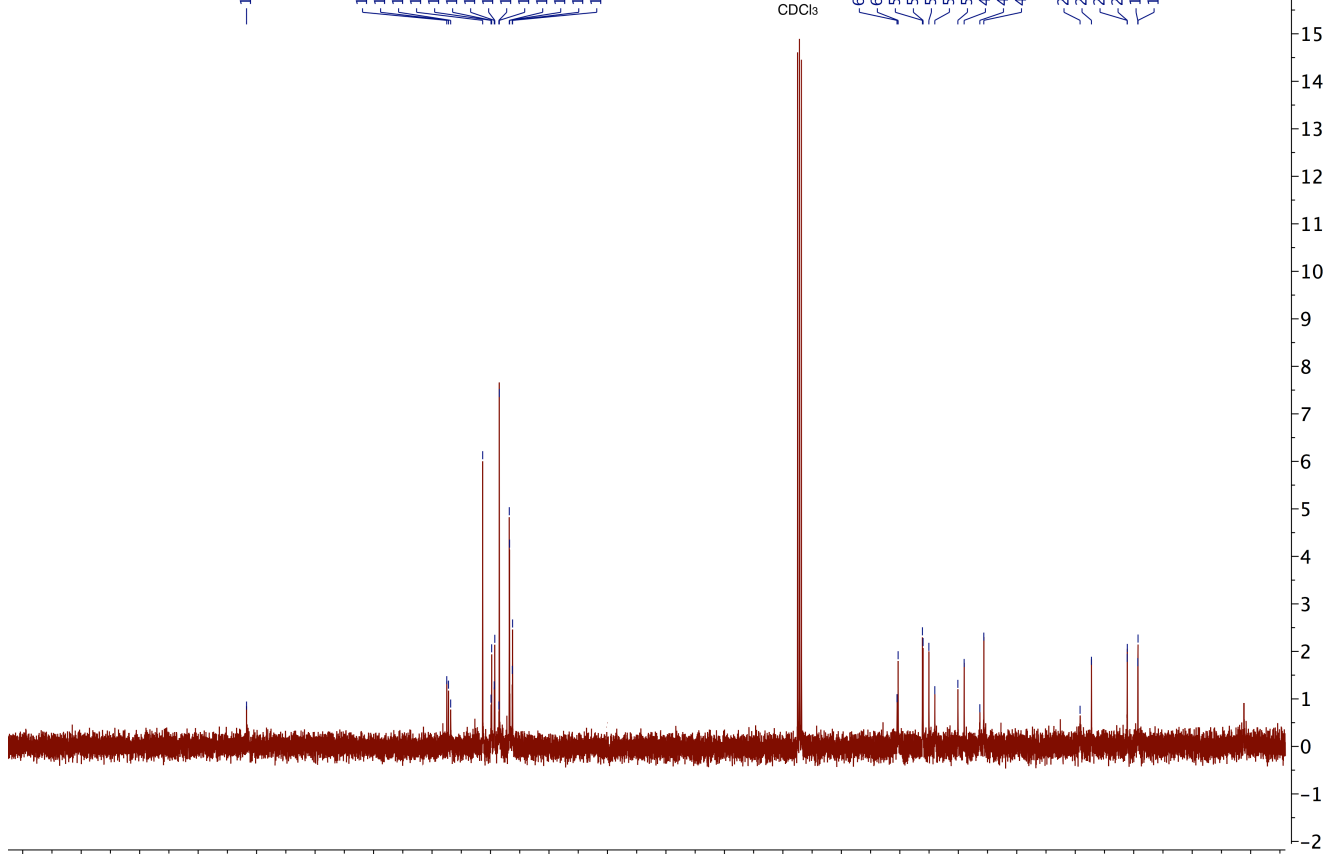

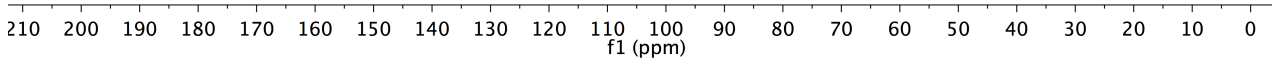




\section{Computational details}

2.1 Protein preparation. We chose chain A of structure $5 \mathrm{HK} 2 .{ }^{1}$ We added missing atoms and residues with Swiss-PDB Viewer. ${ }^{2}$ We performed a steepest descent minimization of the protein chain to be stopped either when the maximum force was lower than $1000.0 \mathrm{~kJ} / \mathrm{mol} / \mathrm{nm}$ or when 50000 minimisation steps were performed with $0.005 \mathrm{~kJ} / \mathrm{mol}$ energy step size, with Verlet cutoff scheme, short-range electrostatic cut-off and Van der Waals cut-off of 1.0nm. We used GROMOS 54a7 force field ${ }^{3}$ and ran the minimisation as implemented in the Gromacs package v. 2016.1. ${ }^{4}$

2.2 Molecule preparation and docking. Molecule initial conformations were protonated, and minimized with AM1 method as implemented in MOPAC. ${ }^{5}$ The system was prepared with AutoDock tools, and docked with AutoDock. ${ }^{6}$ We used Lamarckian Genetic Algorithm with docking box (15.000x15.750x15.00) $\AA$ centered on the hydroxyl oxygen of TYR 103. The docking was performed with 100 runs and 2,500,000 maximum numbers of evaluations and standard parameters. We chose as representative conformation the representative conformation of the most populated cluster. 2D ligandprotein interaction diagrams were generated with LigPlot+.

2.3 Molecular Dynamics Simulations. We minimized the complex by first minimizing the protein side chains alone, then whole protein and finally the whole system by constraining selected portions of the system. We placed the complex in a cubic box with a water layer of $0.7 \mathrm{~nm}$ and performed a second minimization. We used GROMOS 54a7 force field ${ }^{3}$ and Simple Point Charge water. Ligand topologies were built with ATB ${ }^{8}$ For the protein we consider only the extracellular domain (residues 33-209). We performed NVT and NPT equilibrations for 100 ps, followed by $250 \mathrm{~ns}$ NPT production run at $300 \mathrm{~K}$. The iteration time step was set to 2 fs with the Verlet integrator and LINCS $^{9}$ constraint. We used periodic boundary conditions. All the simulations and their analysis were run as implemented in the Gromacs package v. 2016.1. ${ }^{4}$ RMSDs and RMSF have been calculated from configurations sampled every 10 ps and as running averages over 100 sampled points. Autodock Vina scorings ${ }^{10}$ were calculated over configurations sampled every $100 \mathrm{ps}$ and as running averages over 10 points. 2D ligand-protein interaction diagrams were generated with LigPlot $+{ }^{7}$ The binding free energy was estimated with the MM/PBSA method, with the apolar solvation energy calculated as solvent accessible surface area (SASA) and default parameters, as implemented in the g_mmpbsa tool. ${ }^{11}$ Simulations were run on Marconi (CINECA, Italy). 


\section{Binding studies}

\subsection{Materials}

Guinea pig brains, rat brains and rat livers were commercially available (Harlan-Winkelmann, Borchen, Germany). Pig brains were a donation of the local slaughterhouse (Coesfeld, Germany). The recombinant L(tk-) cells stably expressing the GluN2B receptor were obtained from Prof. Dr. Dieter Steinhilber (Frankfurt, Germany). Homogenizers: Elvehjem Potter (B. Braun Biotech International, Melsungen, Germany) and Soniprep ${ }^{\circledR} 150$ (MSE, London, UK). Centrifuges: Cooling centrifuge model Eppendorf 5427R (Eppendorf, Hamburg, Germany) and High-speed cooling centrifuge model Sorvall ${ }^{\circledR}$ RC-5C plus (Thermo Fisher Scientific, Langenselbold, Germany). Multiplates: standard 96 well multiplates (Diagonal, Muenster, Germany). Shaker: self-made device with adjustable temperature and tumbling speed (scientific workshop of the institute). Harvester: MicroBeta ${ }^{\circledR}$ FilterMate 96 Harvester. Filter: Printed Filtermat Typ A and B. Scintillator: Meltilex ${ }^{\circledR}$ (Typ A or B) solid state scintillator. Scintillation analyzer: MicroBeta ${ }^{\circledR}$ Trilux (all Perkin Elmer LAS, Rodgau-Jügesheim, Germany).

\subsection{Preparation of membrane homogenates from pig brain cortex}

Fresh pig brain cortex was homogenized with the potter $(500-800 \mathrm{rpm}, 10$ up and down strokes) in 6 volumes of cold $0.32 \mathrm{M}$ sucrose. The suspension was centrifuged at $1,200 \mathrm{x} \mathrm{g}$ for $10 \mathrm{~min}$ at $4{ }^{\circ} \mathrm{C}$. The supernatant was separated and centrifuged at $31,000 \mathrm{x}$ g for $20 \mathrm{~min}$ at $4{ }^{\circ} \mathrm{C}$. The pellet was resuspended in 5-6 volumes of TRIS/EDTA buffer ( $5 \mathrm{mM}$ TRIS/1 $\mathrm{mM}$ EDTA, $\mathrm{pH} 7.5)$ and centrifuged again at $31,000 \mathrm{x} \mathrm{g}\left(20 \mathrm{~min}, 4^{\circ} \mathrm{C}\right)$. The final pellet was resuspended in $5-6$ volumes of buffer and frozen $\left(-80{ }^{\circ} \mathrm{C}\right)$ in $1.5 \mathrm{~mL}$ portions containing about $0.8 \mathrm{mg}$ protein $/ \mathrm{mL}$.

\subsection{Preparation of membrane homogenates from rat liver}

Two rat livers were cut into small pieces and homogenized with the potter (500-800 rpm, 10 up and down strokes) in 6 volumes of cold $0.32 \mathrm{M}$ sucrose. The suspension was centrifuged at 1,200 x g for $10 \mathrm{~min}$ at $4{ }^{\circ} \mathrm{C}$. The supernatant was separated and centrifuged at $31,000 \mathrm{x}$ g for $20 \mathrm{~min}$ at $4{ }^{\circ} \mathrm{C}$. The pellet was resuspended in 5-6 volumes of buffer (50 mM TRIS, $\mathrm{pH} \mathrm{8.0)}$ and incubated at $\mathrm{rt}$ for $30 \mathrm{~min}$. After the incubation, the suspension was centrifuged again at $31,000 \mathrm{x} \mathrm{g}$ for $20 \mathrm{~min}$ at $4{ }^{\circ} \mathrm{C}$. The final pellet was resuspended in 5-6 volumes of buffer and stored at $-80{ }^{\circ} \mathrm{C}$ in $1.5 \mathrm{~mL}$ portions containing about $2 \mathrm{mg}$ $\operatorname{protein} / \mathrm{mL}$.

\subsection{Cell culture and preparation of membrane homogenates for the GluN2B ${ }^{12}$}

Mouse L(tk-) cells stably transfected with the dexamethasone-inducible eukaryotic expression vectors pMSG GluN1a, pMSG GluN2B (1:5 ratio) were grown in Modified Earl's Medium (MEM) containing $10 \%$ of standardized FCS (Biochrom AG, Berlin, Germany). The expression of the NMDA receptor at the cell surface was induced after the cell density of the adherent growing cells had reached approximately $90 \%$ of confluency. For the induction, the original growth medium was replaced by growth medium containing $4 \mu \mathrm{M}$ dexamethasone and $4 \mu \mathrm{M}$ ketamine (final concentration). After $24 \mathrm{~h}$, the cells were rinsed with phosphate buffered saline solution (PBS, Biochrom AG, Berlin, Germany), harvested by mechanical detachment and pelleted (10 min, 5,000xg).

For the binding assay, the cell pellet was resuspended in PBS solution and the number of cells was determined using a Scepter ${ }^{\circledR}$ cell counter (MERCK Millipore, Darmstadt, Germany). Subsequently, the cells were lysed by sonication ( $4 \mathrm{C}, 6 \times 10$ s cycles with breaks of $10 \mathrm{~s}$ ). The resulting cell fragments were 
centrifuged with a high performance cool centrifuge $(23,500 \mathrm{xg}, 4 \mathrm{C})$. The supernatant was discarded and the pellet was resuspended in a defined volume of PBS yielding cell fragments of approximately 500,000 cells $/ \mathrm{mL}$. The suspension of membrane homogenates was sonicated again $\left(4^{\circ} \mathrm{C}, 2 \mathrm{x} 10 \mathrm{~s}\right.$ cycles with a break of $10 \mathrm{~s}$ ) and stored at $-80{ }^{\circ} \mathrm{C}$.

\subsection{Protein determination}

The protein concentration was determined by the method of Bradford ${ }^{13}$ modified by Stoscheck. ${ }^{14}$ The Bradford solution was prepared by dissolving $5 \mathrm{mg}$ of Coomassie Brilliant Blue G 250 in $2.5 \mathrm{~mL}$ of EtOH $(95 \%, v / v) .10 \mathrm{~mL}$ deionized $\mathrm{H}_{2} \mathrm{O}$ and $5 \mathrm{~mL}$ phosphoric acid $(85 \%, \mathrm{~m} / \mathrm{v})$ were added to this solution, the mixture was stirred and filled to a total volume of $50 \mathrm{~mL}$ with deionized water. The calibration was carried out using bovine serum albumin as a standard in 9 concentrations $(0.1,0.2,0.4$, $0.6,0.8,1.0,1.5,2.0$ and $4.0 \mathrm{mg} / \mathrm{mL})$. In a 96 well standard multiplate, $10 \mu \mathrm{L}$ of the calibration solution or $10 \mu \mathrm{L}$ of the membrane receptor preparation were mixed with $190 \mu \mathrm{L}$ of the Bradford solution, respectively. After $5 \mathrm{~min}$, the UV absorption of the protein-dye complex at $\lambda=595 \mathrm{~nm}$ was measured with a plate reader (Tecan Genios ${ }^{\circledR}$, Tecan, Crailsheim, Germany).

\subsection{General procedures for the binding assays}

The test compound solutions were prepared by dissolving approximately $10 \mu \mathrm{mol}$ (usually $2-4 \mathrm{mg}$ ) of test compound in DMSO so that a $10 \mathrm{mM}$ stock solution was obtained. To obtain the required test solutions for the assay, the DMSO stock solution was diluted with the respective assay buffer. The filtermats were presoaked in $0.5 \%$ aqueous polyethylenimine solution for $2 \mathrm{~h}$ at $\mathrm{rt}$ before use. All binding experiments were carried out in duplicates in the 96 well multiplates. The concentrations given are the final concentration in the assay. Generally, the assays were performed by addition of $50 \mu \mathrm{L}$ of the respective assay buffer, $50 \mu \mathrm{L}$ of test compound solution in various concentrations $\left(10^{-5}, 10^{-6}, 10^{-7}, 10^{-8}\right.$, $10^{-9}$ and $\left.10^{-10} \mathrm{~mol} / \mathrm{L}\right), 50 \mu \mathrm{L}$ of the corresponding radioligand solution and $50 \mu \mathrm{L}$ of the respective receptor preparation into each well of the multiplate (total volume $200 \mu \mathrm{L}$ ). The receptor preparation was always added last. During the incubation, the multiplates were shaken at a speed of 500-600 rpm at the specified temperature. Unless otherwise noted, the assays were terminated after 120 min by rapid filtration using the harvester. During the filtration, each well was washed five times with $300 \mu \mathrm{L}$ of water. Subsequently, the filtermats were dried at $95^{\circ} \mathrm{C}$. The solid scintillator was melted on the dried filtermats at a temperature of $95^{\circ} \mathrm{C}$ for $5 \mathrm{~min}$. After solidifying of the scintillator at $\mathrm{rt}$, the trapped radioactivity in the filtermats was measured with the scintillation analyzer. Each position on the filtermat corresponding to one well of the multiplate was measured for $5 \mathrm{~min}$ with the $\left[{ }^{3} \mathrm{H}\right]$-counting protocol. The overall counting efficiency was $20 \%$. The $\mathrm{IC}_{50}$ values were calculated with the program GraphPad Prism ${ }^{\circledR} 3.0$ (GraphPad Software, San Diego, CA, USA) by non-linear regression analysis. Subsequently, the $I C_{50}$ values were transformed into $K_{\mathrm{i}}$ values using the equation of Cheng and Prusoff. ${ }^{15}$ The $K_{\mathrm{i}}$ values are given as mean value \pm SEM from three independent experiments.

\subsection{Performance of the binding assays}

\subsubsection{Ifenprodil binding site of GluN2B subunit containing NMDA receptors}

The competitive binding assay was performed with the radioligand $\left[{ }^{3} \mathrm{H}\right]$ ifenprodil $(60 \mathrm{Ci} / \mathrm{mmol}$; BIOTREND, Cologne, Germany). The thawed cell membrane preparation from the transfected L(tk-) cells (about $20 \mu \mathrm{g}$ protein) was incubated with various concentrations of test compounds, $5 \mathrm{nM}$ $\left[{ }^{3} \mathrm{H}\right]$-ifenprodil, and TRIS/EDTA-buffer (5 mM TRIS/1 mM EDTA, pH 7.5) at $37{ }^{\circ} \mathrm{C}$. The non-specific binding was determined with $10 \mu \mathrm{M}$ unlabeled ifenprodil. The $K_{\mathrm{d}}$ value of ifenprodil is $7.6 \mathrm{nM} .{ }^{12}$ 


\subsection{2 $\sigma_{1}$ receptor assay}

The assay was performed with the radioligand $\left[{ }^{3} \mathrm{H}\right]-(+)$-pentazocine $(22.0 \mathrm{Ci} / \mathrm{mmol}$; Perkin Elmer $)$. The thawed membrane preparation of guinea pig brain cortex (about $100 \mu \mathrm{g}$ of the protein) was incubated with various concentrations of test compounds, $2 \mathrm{nM}\left[{ }^{3} \mathrm{H}\right]-(+)$-pentazocine, and TRIS buffer $(50 \mathrm{mM}$, $\mathrm{pH} 7.4)$ at $37^{\circ} \mathrm{C}$. The non-specific binding was determined with $10 \mu \mathrm{M}$ unlabeled (+)-pentazocine. The $K_{\mathrm{d}}$ value of (+)-pentazocine is $2.9 \mathrm{nM}^{16}$

\subsection{3 $\sigma_{2}$ receptor assay}

The assays were performed with the radioligand $\left[{ }^{3} \mathrm{H}\right] \mathrm{di}-o$-tolylguanidine (specific activity $50 \mathrm{Ci} / \mathrm{mmol}$; ARC, St. Louis, MO, USA). The thawed rat liver membrane preparation (about $100 \mu \mathrm{g}$ protein) was incubated with various concentrations of the test compound, $3 \mathrm{nM}\left[{ }^{3} \mathrm{H}\right] \mathrm{di}$-o-tolylguanidine and buffer containing (+)-pentazocine (500 nM (+)-pentazocine in TRIS buffer (50 mM TRIS, pH 8.0)) at rt. The non-specific binding was determined with $10 \mu \mathrm{M}$ non-labeled di-o-tolylguanidine. The $K_{\mathrm{d}}$ value of di- $o$ tolylguanidine is $17.9 \mathrm{nM}^{17}$ 


\section{Cytotoxicity assay}

The human SH-SY5Y (neuroblastoma), and PANC1 (pancreatic carcinoma) cell lines were maintained in Dulbecco's modified Eagle's medium (DMEM) Glutamax (Life Technologies) supplemented with $10 \%(\mathrm{v} / \mathrm{v})$ fetal bovine serum (FBS) and 1x Antibiotic Antimycotic Solution (Sigma-Aldrich, $100 \mathrm{U}$ penicillin, $100 \mu \mathrm{g} / \mathrm{mL}$ streptomycin and $0.25 \mu \mathrm{g} / \mathrm{mL}$ amphotericin $\mathrm{B}$ ) at $37^{\circ} \mathrm{C}$ in a humidified incubator with a $5 \% \mathrm{CO}_{2} / 95 \%$ air atmosphere. The cytotoxic effects of the compounds were evaluated by MTT test as previously described ${ }^{18}$. Briefly, SH-SY5Y cells or PANC1 cells were plated $\left(5 \times 10^{3}\right.$ cells/well) in $96-$ well plates $24 \mathrm{~h}$ prior to treatment with the compounds. The compounds, dissolved in DMSO, were serially diluted in culture medium to achieve the desired final concentrations. The final concentration of DMSO in the culture medium was always $=1.0 \%$. After $48 \mathrm{~h}$, the medium was replaced with $100 \mu 1 /$ well of MTT in DMEM $(0.75 \mathrm{mg} / \mathrm{mL}$, Sigma-Aldrich, St. Louis, MO, USA), and plates were incubated for 4 $\mathrm{h}$ at $37^{\circ} \mathrm{C}$. After incubation, the medium was carefully removed and plates were incubated at $-20^{\circ} \mathrm{C}$ for 1h. Subsequently, $100 \mu \mathrm{L}$ of isopropanol $100 \%$ was added into each well and the plates were shaked on an orbital shaker for 15 minutes. Absorbances were read in an EnVision Multilabel Plate Reader (PerkinElmer, Waltham, MA, USA) at $590 \mathrm{~nm}$ with a reference filter of $650 \mathrm{~nm}$. All compounds were assayed in triplicates, and the results are the average of three independent experiments. Results are shown as mean absorbance values (A590 subtracted by A650) \pm SEM. Cell viability is expressed as a percentage of the control (DMSO). The statistical analysis was performed with GraphPad Prism 6 (GraphPad Software, Inc, La Jolla, CA, USA) software by using an unpaired t-test. P values $<0.05$ were considered statistically significant.

Table S1. Percentage viability \pm SEM of the SH-SY5Y cells treated with four different concentrations of the title compounds $\mathbf{2 c}, \mathbf{2 d}, \mathbf{3 c}$ and $\mathbf{3 d}$.

\begin{tabular}{lllll}
\hline Cmpd & \multicolumn{3}{c}{ SH-SY5Y } \\
\cline { 2 - 5 } & $12.5 \mu \mathrm{M}$ & $25 \mu \mathrm{M}$ & $50 \mu \mathrm{M}$ & $100 \mu \mathrm{M}$ \\
\hline $\mathbf{2 c}$ & $134 \pm 20$ & $143 \pm 21$ & $127 \pm 19$ & $98 \pm 15$ \\
$\mathbf{2 d}$ & $136 \pm 20$ & $144 \pm 22$ & $131 \pm 20$ & $122 \pm 18$ \\
$\mathbf{3 c}$ & $137 \pm 21$ & $121 \pm 18$ & $109 \pm 16$ & $77 \pm 11$ \\
$\mathbf{3 d}$ & $123 \pm 18$ & $120 \pm 18$ & $127 \pm 19$ & $53 \pm 8$ \\
\hline
\end{tabular}

Table S2. \% Percentage viability \pm SEM of the PANC1 cells treated with four different concentrations of the title compounds $\mathbf{2 c}, \mathbf{2 d}, \mathbf{3 c}$ and $\mathbf{3 d}$.

\begin{tabular}{lllll}
\hline Cmpd & \multicolumn{3}{c}{ PANC1 } \\
\cline { 2 - 5 } & $12.5 \mu \mathrm{M}$ & $25 \mu \mathrm{M}$ & $50 \mu \mathrm{M}$ & $100 \mu \mathrm{M}$ \\
\hline 2c & $258 \pm 36$ & $278 \pm 39$ & $196 \pm 27$ & $127 \pm 18$ \\
2d & $185 \pm 26$ & $188 \pm 26$ & $130 \pm 18$ & $107 \pm 15$ \\
3c & $224 \pm 31$ & $214 \pm 30$ & $201 \pm 28$ & $88 \pm 12$ \\
3d & $121 \pm 17$ & $119 \pm 17$ & $93 \pm 13$ & $51 \pm 7$ \\
\hline
\end{tabular}




\section{Antioxidant activity}

\subsection{ABTS radical scavenging activity}

The antioxidant activity of the compounds was tested from the bleaching of the green colored ethanolic solution of ABTS. ${ }^{19}$ To $1.8 \mathrm{~mL}$ of ethanolic solution of ABTS $7 \mathrm{mM} 200 \mu \mathrm{L}$ of test compounds, each one diluted according the following concentration $0.05,0.1,0.2$ and $0.4 \mathrm{mg} / \mathrm{mL}$. These mixtures were incubated for $40 \mathrm{~min}$ at room temperature, then the absorbances were recorded at $735 \mathrm{~nm}$ against ABTS solution. The results were measured as the percent of inhibition (IC\%) of ABTS radical, calculated by the following formula.

$\% \mathrm{IC}=[($ Abs ABTS - Abs Sample $) /$ Abs ABTS $] \times 1$

Tests were performed in triplicate and data were expressed ad mean value \pm SEM.

The IC \% was used to determine the $\mathrm{IC}_{50}$ values.

The ABTS method was applied also to measure the $\mathrm{IC}_{50}$ of Ascorbic acid, used as antioxidant compound comparing value.

\subsection{Hydrogen peroxide radical scavenging activity}

Four different concentrations of test compounds $(0.05,0.1,0.2$ and $0.4 \mathrm{mg} / \mathrm{mL})$ were diluted in phosphate

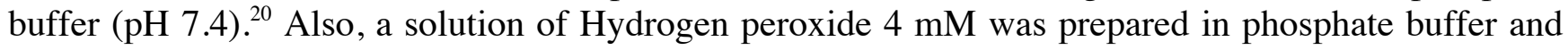
$0.353 \mathrm{~mL}$ of this solution were added to $2.0 \mathrm{~mL}$ of each solution of test compounds. The mixtures were measured at $239 \mathrm{~nm}$. The percent of inhibition of free radical production from hydrogen peroxide was calculated using the above formula.

Tests were performed in triplicate and data were expressed as mean value \pm SEM.

Table S3. Antioxidant activity of compounds $2 \mathrm{c}, \mathbf{2 d}, \mathbf{3 c}$ and $\mathbf{3 d}$.

\begin{tabular}{lll}
\hline Cmpd & $\mathrm{IC}_{50}(\mu \mathrm{g} / \mathrm{mL})^{\mathrm{a}}$ \\
\cline { 2 - 3 } & $\mathrm{ABTS}$ & $\mathrm{H}_{2} \mathrm{O}_{2}$ \\
\hline 2c & $12.71 \pm 0.25$ & $15.89 \pm 0.18$ \\
2d & $14.26 \pm 0.15$ & $20.35 \pm 0.27$ \\
3c & $10.05 \pm 0.09$ & $18.56 \pm 0.31$ \\
3d & $9.43 \pm 0.11$ & $17.44 \pm 0.18$ \\
Ascorbic Acid & $12.75 \pm 0.12$ & $19.27 \pm 0.54$ \\
Trolox & $18.73 \pm 0.26$ & $20.38 \pm 0.19$ \\
\hline
\end{tabular}

${ }^{a}$ All measurements were performed in triplicate 


\section{Drug likeness prediction}

Table SI 4. In silico predicted main pharmacokinetic parameters ${ }^{21}$ (www.swissadme.ch) of the title compounds 2a-g and 3a-g. Data for reference compound Haloperidol ( $\sigma 1$ ligand) and Siramesine ( $\sigma 2$ ligand) are reported for comparison.

\begin{tabular}{|c|c|c|c|c|c|c|c|c|c|c|}
\hline Cmpd & & $\mathrm{MW}^{\mathrm{b}}$ & $\mathrm{HBA}^{\mathrm{c}}$ & $\mathrm{HBD}^{\mathrm{d}}$ & $\operatorname{clog} \mathrm{P}^{\mathrm{e}}$ & $\begin{array}{l}\operatorname{clog}^{f} S^{f} \\
(\mathrm{~mol} / \mathrm{L})\end{array}$ & $\begin{array}{l}\text { TPSA }^{\mathrm{g}} \\
(\AA<140)\end{array}$ & $\begin{array}{l}\text { RO5 } \\
\text { violation }\end{array}$ & $\begin{array}{l}\text { BBB } \\
\text { permeant }\end{array}$ & $\begin{array}{l}\text { GI } \\
\text { abs. }\end{array}$ \\
\hline & $\mathrm{RO}^{\mathrm{a}}$ & $<500$ & $\leq 10$ & $\leq 5$ & $\leq 5$ & $\leq 5$ & - & $\leq 1$ & - & - \\
\hline $2 a$ & & 284.35 & 3 & 0 & 2.22 & -3.26 & 36.69 & 0 & Yes & High \\
\hline $2 b$ & & 300.42 & 2 & 0 & 2.89 & -3.75 & 51.79 & 0 & Yes & High \\
\hline $2 c$ & & 334.41 & 3 & 0 & 3.25 & -4.47 & 36.69 & 0 & Yes & High \\
\hline $2 d$ & & 345.44 & 3 & 0 & 3.22 & -4.47 & 36.44 & 0 & Yes & High \\
\hline $2 e$ & & 295.38 & 3 & 0 & 2.10 & -3.05 & 36.44 & 0 & Yes & High \\
\hline $2 f$ & & 344.45 & 2 & 0 & 3.68 & -4.87 & 23.55 & 0 & Yes & High \\
\hline $2 g$ & & 294.39 & 2 & 0 & 2.84 & -3.72 & 23.55 & 0 & Yes & High \\
\hline $\mathbf{3 a}$ & & 312.41 & 3 & 0 & 2.86 & -3.86 & 36.69 & 0 & Yes & High \\
\hline $3 b$ & & 328.47 & 2 & 0 & 3.56 & -4.35 & 51.79 & 0 & Yes & High \\
\hline $3 c$ & & 362.46 & 3 & 0 & 3.84 & -5.08 & 36.69 & 0 & Yes & High \\
\hline 3d & & 373.49 & 3 & 0 & 3.77 & -5.07 & 36.44 & 0 & Yes & High \\
\hline $3 e$ & & 323.43 & 3 & 0 & 2.73 & -3.65 & 36.44 & 0 & Yes & High \\
\hline 3f & & 372.50 & 2 & 0 & 4.36 & -5.47 & 23.55 & 0 & Yes & High \\
\hline $3 g$ & & 322.44 & 2 & 0 & 3.51 & -4.32 & 23.55 & 0 & Yes & High \\
\hline Halop. & & 375.86 & 4 & 1 & 4.22 & -4.82 & 40.54 & 0 & Yes & High \\
\hline SRMS & & 454.59 & 3 & 0 & 5.85 & -6.52 & 17.40 & 1 & No & Low \\
\hline
\end{tabular}

[a] Lipinski's rule of five; [b] Molecular weight; [c] \# of hydrogen bond acceptors; [d] \# of hydrogen bond donors; [e] calculated log partition coefficient; [f] calculated log of water solubility; [g] topological polar surface area. 


\section{References}

1. Schmidt, H.R. et al., Crystal structure of the human $\sigma 1$ receptor. Nature, 2016, 532, 527-530.

2. Guex, N. and M.C. Peitsch, Swiss model and the Swiss-Pdb Viewer: an environment for comparative protein modeling. Electrophoresis, 1997, 18, 2714-2723.

3. Schmid, N. et al., Definition and testing of the GROMOS force-field versions 54A7 and 54B7. Eur. Biophys. J. 2011, 40, 843-856.

4. Pronk, S. et al., GROMACS 4.5: a high-throughput and highly parallel open source molecular simulation toolkit. Bioinf. 2013, 29, 845-854.

5. Stewart, J.J.P., Special issue - MOPAC - A semiempirical molecular-orbital program. $J$. Comput. Aided Mol. Des. 1990, 4, 1-45.

6. Morris, G.M. et al., AutoDock4 and AutoDockTools4: Automated docking with selective receptor flexibility. J. Comput. Chem. 2009, 30, 2785-2791.

7. Laskowski, R.A. and M.B. Swindells, LigPlot+: multiple ligand-protein interaction diagrams for drug discovery, J. Chem. Inf. Model. 2011, 24, 2778-2786.

8. Malde, A.K. et al., An Automated Force Field Topology Builder (ATB) and Repository: Version 1.0. J. Chem. Theory Comput., 2011, 7, 4026-4037.

9. Hess, B. et al., LINCS: a linear constraint solver for molecular simulations. J. Comput. Chem. 1997, 18,1463-1472.

10. Trott, O. and A.J. Olson, AutoDock Vina: improving the speed and accuracy of docking with a new scoring function, efficient optimization, and multithreading. J. Comput. Chem. 2010, 31, 455461.

11. Kumari, R. et al., g_mmpbsa A GROMACS tool for high-throughput MM-PBSA calculations. J. Chem. Inf. Model. 2014, 54, 1951-1962.

12. Schepmann, D. et al., Development of a selective competitive receptor binding assay for the determination of the affinity to NR2B containing NMDA receptors, J. Pharm. Biomed. Anal. 2010, 53, 603-608.

13. Bradford, M.M. A Rapid and sensitive Method for the Quantitation of Microgram Quantities of Protein Utilizing the Principle of Protein-Dye Binding, Anal. Biochem. 1976, 72, 248-254.

14. Stoscheck, C. Quantification of Protein, Methods in Enzymology, 1990, 182, 50-68.

15. Cheng, Y.C. and Prusoff, W.H. Relationship between the inhibition constant (KI) and the concentration of inhibitor which causes 50 per cent inhibition (I50) of an enzymatic reaction, Biochem. Pharmacol. 1973, 22, 3099-3108

16. DeHaven-Hudkins, D.L. et al., Characterization of the binding of $[3 \mathrm{H}](+)$-pentazocine to sigma recognition sites in guinea pig brain, Eur. J. Pharmacol.: Molecular Pharmacology 1992, 1227, 371-378.

17. Mach, R.H. et al. Ibogaine possesses a selective affinity for sigma 2 receptors, Life Sciences 1995, 57, PL57-PL62.

18. Zampieri, D. et al., Computer-assisted design, synthesis, binding and cytotoxicity assessments of new 1-(4-(aryl(methyl)amino)butyl)-heterocyclic $\sigma 1$ ligands, Eur. J. Med Chem. 2016, 121, 712726.

19. Re, R. et al, Antioxidant activity applying an improved ABTS radical cation decolorization assay, Free radical biology \& medicine 1999, 26, 1231-1237.

20. Ashok, D. et al., Conventional and microwave-assisted synthesis of new indole-tethered benzimidazole-based 1,2,3-triazoles and evaluation of their antimycobacterial, antioxidant and antimicrobial activities, Mol. Divers. 2018, 22, 769-778.

21. Daina, A et al., SwissADME: a free web tool to evaluate pharmacokinetics, drug-likeness and medicinal chemistry friendliness of small molecules, Sci. Report 2017, 7, 42717. 